$$
\begin{gathered}
\text { THIS IS A POST } \\
\text { PRINT } \\
\text { Published in journal } \\
\text { Geocarto International }
\end{gathered}
$$




\title{
Land Use/Land Cover in view of Earth Observation: Data Sources, Input Dimensions and Classifiers -a Review of the State of the Art
}

Prem Chandra Pandey ${ }^{1, *}$, Nikos Koutsias ${ }^{2}$, George P. Petropoulos ${ }^{3,4}$, Prashant K.

Srivastava ${ }^{5}$, Eyal Ben Dor ${ }^{6}$

6

${ }^{1}$ Center for Environmental Sciences and Engineering, School of Natural Sciences, Shiv Nadar University, Greater Noida Dadri, Gautam Buddha Nagar Uttar Pradesh, India-201314; prem26bit@gmail.com; prem.pandey@snu.edu.in

${ }^{2}$ Department of Environmental and Natural Resources Management, University of Patras, G. Seferi 2, GR-30100, Agrinio, Greece; nkoutsia@upatras.gr

${ }^{3}$ School of Mineral \& Resources Engineering, Technical University of Crete, Crete, Greece

${ }^{4}$ Department of Soil \& Water Resources, Institute of Industrial \& Forage Crops, Hellenic Agricultural Organization "Demeter", Larisa, Greece

Email:petropoulos.george@gmail.com

${ }^{5}$ Institute of Environment and Sustainable Development, Banaras Hindu University, Varanasi, India221005; , email: prashant.iesd@bhu.ac.in

${ }^{6}$ Department of Geography, School of Geo-Sciences, Faculty of Exact Sciences, Tel Aviv University, Israel-6997801; bendor@post.tau.ac.il bendor@tauex.tau.ac.il

* Corresponding author: Email: prem26bit@gmail.com

\begin{abstract}
Land use/Land cover (LULC) is a fundamental concept of the Earth's system intimately connected to many phases of the human and physical environment. Earth Observation (EO) technology provides an informative source of data covering the entire globe in a spatial and spectral resolution appropriate to better and easier classify land cover than traditional or conventional methods. The use of high spatial and spectral resolution imagery from EO sensors has increased remarkably over the past decades, as more and more platforms are placed in orbit and new applications emerge in different disciplines.
\end{abstract}

The aim of the present review work is to provide all-inclusive critical reflection on the state of the art in the use of EO technology in LULC mapping and change detection. The emphasis is placed on providing an overview of the different EO datasets, spatial-spectral-temporal characteristics of satellite data and classification approaches employed in land cover classification. The review concludes providing recommendations and remarks on what should be done in order to overcome hurdle faced using above-mentioned problems in LULC mapping. This also provides information on using classifier algorithms depending upon the data types and dependent on the regional ecosystems.

One of the main messages of our review is that in future, there will be a need to assemble techniques specifically used in LULC with their merit and demerits that will enable more comprehensive understanding at regional or global scale and improve understanding between different land cover relationship and variability among them and these remains to be seen.

Keywords: LULC mapping; Landsat; Hyperspectral; spatial-spectral dimensions; Multi-temporal; multi-source 


\subsection{Introductory concepts}

Land Use/Land Cover (LULC) and its changes has been considered as one of the factor of global environmental change (Erdogan et al. 2015). Accurate identification and monitoring of LULC is important for land resource management, since LULC mapping constitutes an important part of the land management system (Chatziantoniou et al. 2017). Land cover demonstrates the terrain features on the Earth surface whereas land use reflects the utilization of available land by the human beings i.e. built environment/human use of terrains (Fisher et al. 2005; Hansen and Loveland 2012). Accurate knowledge of LULC provides critical information for planning and management activities (Elatawneh 2015). This is attributed to the fact that land is one of the most important natural resource of the earth system contributing to life and various other development activities (Whyte et al. 2018).

LULC information and its spatial distribution patterns are essential for a wide spectrum of research themes especially urban studies characterized by heterogeneous classes and for maintenance and developmental plans (Stefanov et al. 2001). LULC change has been perceived as a key driver of worldwide environmental change by affecting the land surface (Petropoulos et al. 2013). Being in steady change, urban perimeter, river basins, wetlands, agricultural areas are constantly subjected to LULC changes, particularly by decreasing forest cover to give a path for agricultural extension, urbanization, industrialization and so on (Stamou et al. 2016). Land cover in urban environments is changing rapidly and conversion from agricultural/fallow to concrete forest resulting in urban sprawl (Pandey et al. 2012), hence play a key role in environment changes (Vargo et al. 2013).

The assessment of LULC and of its change is important for understanding several environmental issues related to urban as well as to surrounding landscapes. The primary impact on many other processes need to be assessed, such as utilisation of land cover, surface temperature variation due to concrete forest, (Rani et al. 2018), habitat fragmentation, biodiversity loss (Trisurat et al. 2010; Theobald et al. 2011), soil and land degradation (Zucca et al. 2010; Bajocco et al. 2012; Pandey et al. 2013), decreased air quality, waste disposal problem (Pandey et al. 2012), decreased water seepage, increased runoff along with subsequent flooding/flash flood, water quality deterioration (Tu 2011; Uriarte et al. 2011), and decreased agricultural productivity. An improved understanding of historical LULC change patterns provides a better means to understand the present and project future trends of LULC change using different remote sensing (RS) datasets at multiple spatial, spectral and temporal resolutions (Pocewicz et al. 2008). One of the key concerns about LULC and its impact has emerged on a global stage due to the realisation that changes occurring on the land surface also influence climate (Mahmood et al. 2014), ecosystem and its services and in return reduces biotic diversity (Dezso et al. 2005). As a result, the requirements for mapping and monitoring LULC at multiple scales are well-suited with demands associated to the EU habitats Directive (Petropoulos et al. 2013; Singh Priyadarshini et al. 2017).

Nowadays remote sensing is the primary sources used extensively for LULC analysis in the recent decades. Remote sensing often combined with Geographic Information System (GIS) has been used extensively in mapping LULC in the analysis of their dynamics (Zucca et al. 2010). Several research works were carried out by considering the importance of LULC changes at multiple scales, for spatiotemporal change patterns and identification of composition and its rate among different study sites (Gessner et al. 2009; Chen G et al. 2012; Modica et al. 2012; Sharma et al. 2012; Grecchi et al. 2014).

87 The purpose of this review is to present LULC classification using multi-sensors, multi-source, multi88 temporal datasets, input dimension and use of classifiers, and present the standard on improving the 
change analysis, depending upon the user needs and requirements according to the landscape or data availability. Figure 1 represents the user inputs, input dimension and classifier algorithms for LULC mapping. The use of more than one data attributes helps in enhancing the results, such as high spatial resolution, high spectral resolution, providing high temporal resolution to study change patterns at a regular interval and may contribute a large coverage of the landscape.

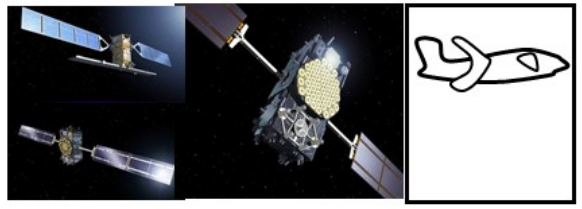

Multi-sensors, multi-source remotely sensed data

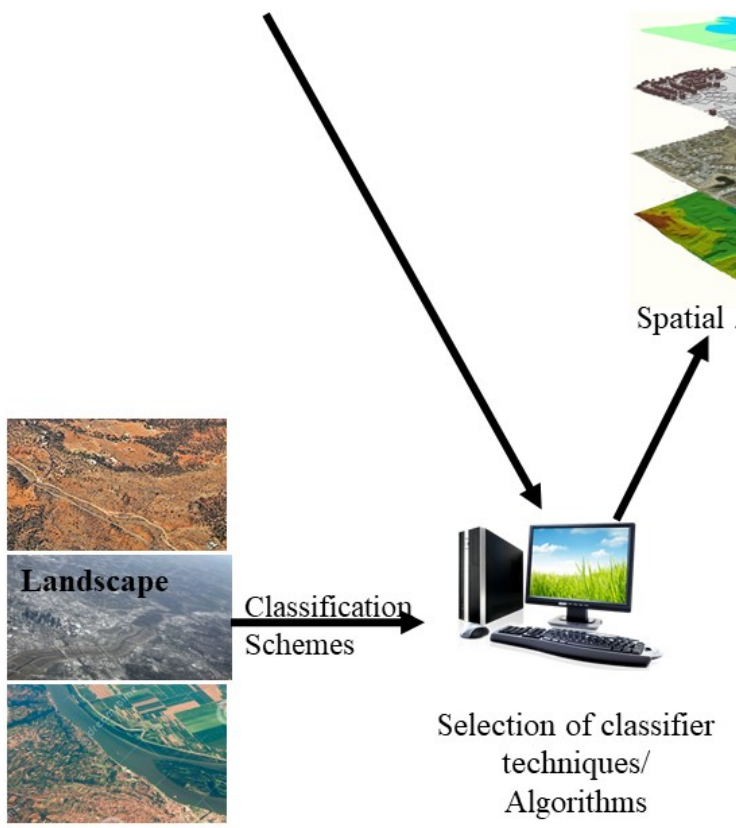

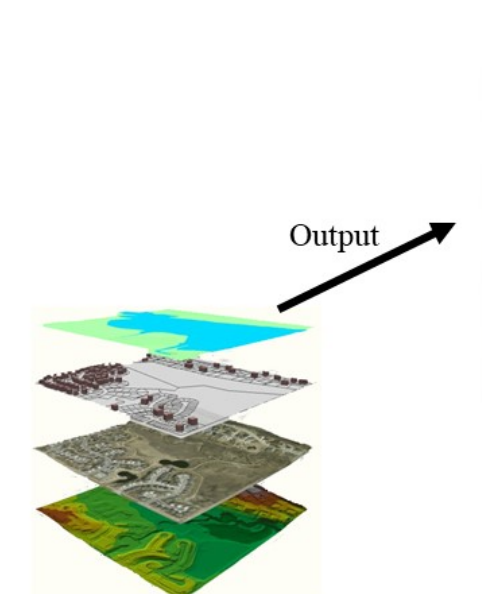

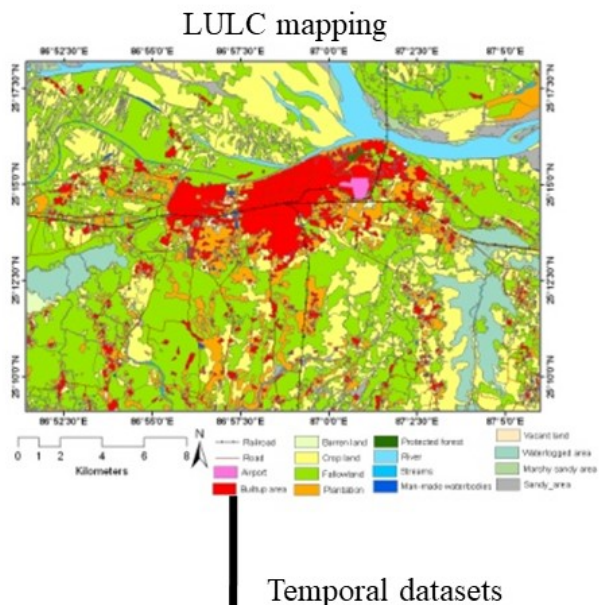

Temporal datasets

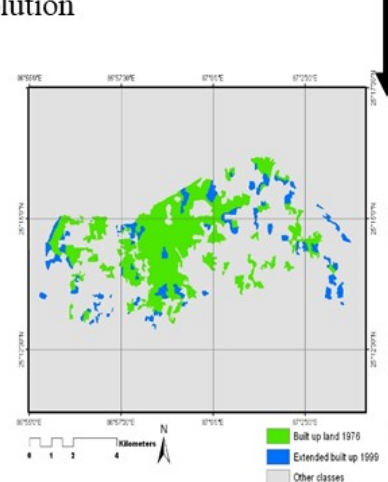

Dynamic changes and patterns

Figure 1 An illustration showing types of datasets, spatio-spectral-temporal dimension and classifiers algorithms for LULC and dynamic changes (author generated figure).

Thus, the objective of this review is two-fold: first to highlight various aspects of LULC classification using multi-sensor, multi-source, multi-temporal datasets, input requirements and use of classifiers and second to present the standard on improving the change analysis, depending upon the user needs and requirements according to the landscape or data availability. In this background, the importance of input dimension, remotely sensed datasets, as well as algorithms is discussed which is certainly dependent upon how they are being utilised during LULC assessment.

\subsection{EO datasets: Multispectral, Hyperspectral, LiDAR, SAR}

Remote sensing has emerged as very powerful technology providing accurate spatial information and LULC distribution in the temporal period (Bora and Goswami 2016; Gidey et al. 2017; Rani et al. 2018; Kabisch et al. 2019). The use of remotely sensed dataset depends upon the user's need, 
110 requirement, and type of assessment of the landscape. While other factors such as regional coverage 111 (either large or small-MODIS, MISR), spatial and spectral (AVIRIS, ASTER, AVHRR), high spatial112 spectral resolution (AISA -airborne hyperspectral images), temporal coverage (LANDSAT TM, MSS, 113 ETM+) and Synthetic Aperture Radar (SAR) data (to counter cloud effects) play an important role in 114 choosing the particular data for a specific type of study (See Figure 2).

115 LULC change patterns and dynamic changes have been presented with conventional methods, 116 individual remote sensing data, multi-sensor, multi-source, multi-sensor-temporal data are widely 117 used for assessment and evaluation of LULC change and patterns of the landscape (Figure 2). More 118 recently the synergy between different Earth Observation (EO) datasets in obtaining LULC mapping 119 has been examined. The motivation behind the synergy of different datasets is to harness the different 120 properties such as spatial, spectral, topographic, texture for improving the accuracy of land cover 121 mapping and temporal for improving the change dynamics. Therefore, user needs and requirements play an important role in the selection of types of remotely sensed datasets, input dimension, and implementing classifiers. With the advancement of EO technology, the broad spectral resolution was replaced with high spectral resolution and filled the gap in limitation of multispectral imaging (Heiden et al. 2007). EO datasets classification along with a range of classification approach varies with the complexity of study site, the content and details of the classification scheme, spatial/spectral resolution of datasets, and thus remains a challenge in the remote sensing community.

128 In overall, remotely sensed data are sharing the stages for LULC change and pattern analysis according to need and availability. The implementation of different remotely sensed data is according to the users' needs and the requirement for large area coverage, high spatial resolution, spectral resolution, temporal resolution or combination of one or more together.

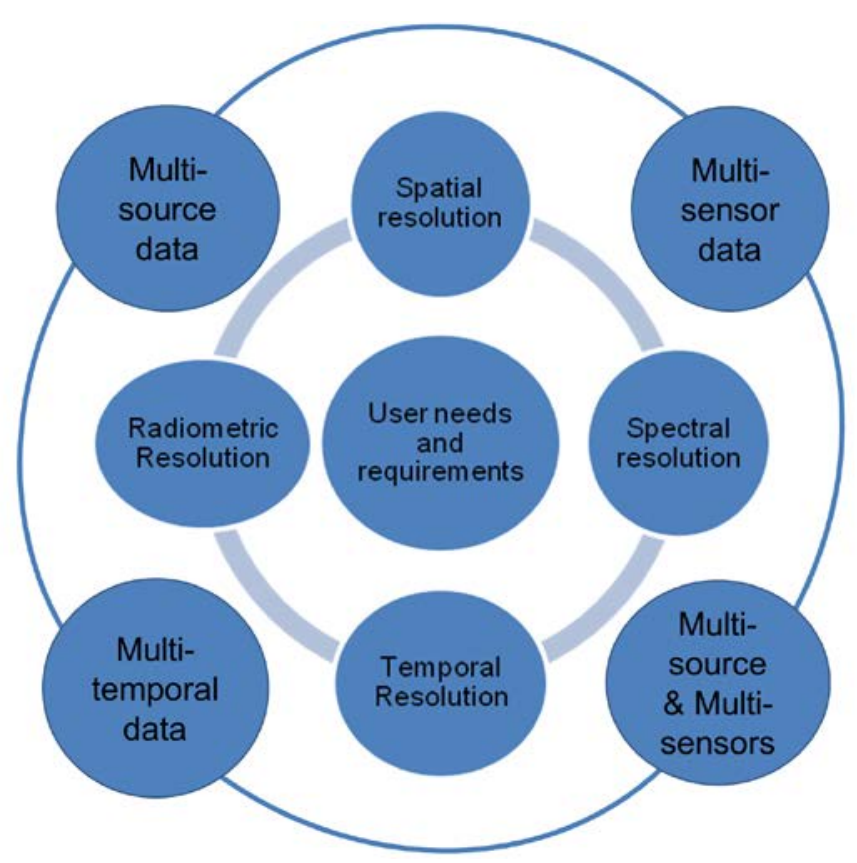

134 Figure 2: Conceptual model to demonstrate the user needs and requirements revolve around the basic characteristics/properties of remotely sensed data and their combinations (author generated figure). 
Table-1: Major space-borne multispectral sensors and their specifications: Sources: (Piwowar 2011; BELSPO 2013; PASCO 2015; ESA 2018)

\begin{tabular}{|c|c|c|c|c|c|c|c|c|c|}
\hline & Sensors & Platform & $\begin{array}{ll}\text { Spectral } & \text { range/ } \\
\text { resolution } & \end{array}$ & $\begin{array}{lll}\text { Spatial/ } & \text { Spectral } & \text { resolution } \\
(\mathrm{m}) & \end{array}$ & Channels & Revisit time & Swath Width & $\begin{array}{l}\text { Organi } \\
\text { zation / } \\
\text { Nation }\end{array}$ & Launch year \\
\hline 1 & $\begin{array}{l}\text { LANDSAT } \\
\text { MSS }\end{array}$ & & $0.5-1.1 \mu \mathrm{m}$ & Optical - $60 \mathrm{~m}$ & 4 Bands & 18 Days & $185 \mathrm{~km}$ & NASA & $\begin{array}{l}\text { LANDSAT } 1(1972) \\
\text { LANDSAT } 2 \text { (1975) } \\
\text { LANDSAT } 3(1983)\end{array}$ \\
\hline 2 & $\begin{array}{l}\text { LANDSAT } \\
\text { TM }\end{array}$ & & $0.45-12.50 \mu \mathrm{m}$ & $\begin{array}{l}\text { Optical - } 30 \mathrm{~m} \text {, } \\
\text { Thermal - } 120 \mathrm{~m}\end{array}$ & 7 Bands & 16 days & $185 \mathrm{~km}$ & NASA & $\begin{array}{l}\text { LANDSAT } 4 \text { (1982) } \\
\text { LANDSAT } 5 \text { (1984) }\end{array}$ \\
\hline 3 & $\begin{array}{l}\text { LANDSAT } \\
\text { ETM }^{+}\end{array}$ & & $0.45-12.50 \mu \mathrm{m}$ & $\begin{array}{l}\text { Optical - } 30 \mathrm{~m} \\
\text { Thermal }-60 \mathrm{~m} \\
\text { Pan }-15 \mathrm{~m}\end{array}$ & 8 Bands & 16 Days & $185 \mathrm{~km}$ & NASA & $\begin{array}{l}\text { LANDSAT } 7 \text { ( } 15 \\
\text { April 1999) }\end{array}$ \\
\hline 4 & $\begin{array}{l}\text { LANDSAT } \\
8\end{array}$ & EO - 1 & $0.43-12.51 \mu \mathrm{m}$ & $\begin{array}{l}\text { Optical - } 30 \mathrm{~m} \text {, } \\
\text { Cirrus - } 30 \mathrm{~m} \\
\text { Pan }-15 \mathrm{~m} \\
\text { Thermal - } 100 \mathrm{~m}\end{array}$ & 11 Bands & 16 Days & $185 \mathrm{~km}$ & NASA & $\begin{array}{c}\text { LANDSAT } 8 \text { (11 Feb } \\
\text { 2013) }\end{array}$ \\
\hline 5 & LISS- I & IRS- 1A, 1B & $0.45-0.86 \mu \mathrm{m}$ & $72 \mathrm{~m}$ & 4 Bands & 22 Days & $148 \mathrm{~km}$ & ISRO & $\begin{array}{c}\text { IRS 1A (17 March } \\
\text { 1988) } \\
\text { IRS 1B (29 Aug 1991) }\end{array}$ \\
\hline 6 & LISS- II & IRS- 1A, 1B & $0.45-0.86 \mu \mathrm{m}$ & $36 \mathrm{~m}$ & 4 Bands & 22 Days & $148 \mathrm{~km}$ & ISRO & $\begin{array}{c}\text { IRS 1A (17 March } \\
\text { 1988) } \\
\text { IRS 1B (29 Aug 1991) }\end{array}$ \\
\hline 7 & LISS- III & $\begin{array}{c}\text { IRS- 1C } \\
\text { ResourceSat- } \\
1\end{array}$ & $0.52-1.70 \mu \mathrm{m}$ & $\begin{array}{l}\text { Green, Red, NIR - } 23 \\
\text { Mid-IR - } 70\end{array}$ & 4 Bands & 24 Days & $\begin{array}{c}142 \text { km (G,R,NIR) } \\
148 \text { km (Mid-IR) } \\
140 \text { km } \\
\text { (ResourceSat-1) }\end{array}$ & ISRO & IRS 1C (28 Dec 1995) \\
\hline 8 & LISS-IV & $\begin{array}{l}\text { ResourceSat- } \\
1\end{array}$ & $0.52-0.86 \mu \mathrm{m}$ & $5.8 \mathrm{~m}$ & 3 Bands & 5 - 24 Days & $70 \mathrm{~km}$ & ISRO & 17 Oct 2003 \\
\hline 9 & SPOT 5 & & $\begin{array}{l}\text { Green: } 0.5-0.59 \mu \mathrm{m} \\
\text { Red:0.61-0.68 } \mu \mathrm{m} \\
\text { Near IR: } 0.78-0.89 \mu \mathrm{m} \\
\text { SWIR: } 1.54 .1 .75 \mu \mathrm{m}\end{array}$ & $\begin{array}{l}5 \mathrm{~m} \mathrm{PAN} \\
2.5-3 \mathrm{~m} \text { on ground } \\
\mathrm{B} 1-\mathrm{B} 2-\mathrm{B} 3=10 \mathrm{M} \\
\mathrm{SWIR}=20 \mathrm{M}\end{array}$ & $\begin{array}{l}1 \text { band (PAN) } \\
4 \text { bands (MS) }\end{array}$ & 2-3 days & $\begin{array}{l}60 \times 60 \mathrm{~km} \text { or } \\
60 \mathrm{~km} \times 120\end{array}$ & France & May 3, 2002 \\
\hline $\begin{array}{l}1 \\
3\end{array}$ & $\begin{array}{l}\text { WorldView- } \\
1\end{array}$ & & $0.45-0.90 \mu \mathrm{m}$ & $\begin{array}{l}50 \mathrm{~cm} \text { (Nadir) - } \\
55 \mathrm{~cm} \text { (off-Nadir) }\end{array}$ & 1 Band (Pan) & $\begin{array}{l}\text { 1.7 Days ( } 1 \mathrm{~m} \text { or less) } \\
\text { 5.9 Days ( } 50 \mathrm{~cm} \\
\text { resolution) }\end{array}$ & 17.6 km (Nadir) & USA & 18 Sept 2007 \\
\hline $\begin{array}{l}1 \\
4\end{array}$ & $\begin{array}{l}\text { WorldView- } \\
2\end{array}$ & & $450-800 \mathrm{~nm}$ & $\begin{array}{l}\text { Pan - } 0.46 \text { (Nadir) } \\
\text { Multispectral - } 1.84 \text { Nadir) }\end{array}$ & $\begin{array}{l}1 \text { Band (Pan) } \\
8 \text { Bands (MS) }\end{array}$ & $\begin{array}{l}\text { 1.1 Days ( } 1 \mathrm{~m} \text { or less) } \\
\text { 3.7 Days ( } 52 \mathrm{~cm} \\
\text { resolution) }\end{array}$ & $16.4 \mathrm{~km}$ & USA & 8 Oct 2009 \\
\hline $\begin{array}{l}1 \\
5\end{array}$ & $\begin{array}{l}\text { WorldView } \\
-3\end{array}$ & & $400-2365 \mathrm{~nm}$ & $\begin{array}{l}\text { Pan }-0.31 \\
\text { Multispectral Nadir- } 1.21 \\
\text { SWIR Nadir }=3.7 \mathrm{~m}\end{array}$ & $\begin{array}{l}1 \text { Band (Pan) } \\
8 \text { Bands (MS) } \\
8 \text { Bands (SWIR) }\end{array}$ & 4.5 Days & $13.1 \mathrm{~km}$ & USA & 13 Aug 2014 \\
\hline
\end{tabular}




\begin{tabular}{|c|c|c|c|c|c|c|c|c|}
\hline & & & CAVIS Nadir $=30 \mathrm{~m}$ & 12 Bands (CAVIS) & & & & \\
\hline $\begin{array}{l}1 \\
6\end{array}$ & $\begin{array}{l}\text { WorldView- } \\
4\end{array}$ & $450-920 \mathrm{~nm}$ & $\begin{array}{c}\text { PAN Nadir }=0.30 \mathrm{~m} \\
\text { Multispectral Nadir }=1.24 \mathrm{~m}\end{array}$ & $\begin{array}{l}1 \text { Band (Pan) } \\
4 \text { Bands (MS) }\end{array}$ & 4.5 Days & $13.1 \mathrm{~km}$ & USA & 11 Nov 2016 \\
\hline $\begin{array}{l}1 \\
7\end{array}$ & Sentinel 1 & $4.0-8.0 \mathrm{~cm}$ & Pan -5 & 1 Band (C-SAR) & 6 Days & $80 \mathrm{~km}$ & ESA & 3 April 2014 \\
\hline $\begin{array}{l}1 \\
8\end{array}$ & Sentinel 2 & $0.44-2.19 \mu \mathrm{m}$ & $10-60$ & 13 Bands & $\begin{array}{c}5 \text { Days (2 Satellite) } \\
10 \text { Days (1 Satellite) }\end{array}$ & $290 \mathrm{~km}$ & ESA & 23 June 2015 \\
\hline $\begin{array}{l}1 \\
9\end{array}$ & $\begin{array}{l}\text { QUICKBIR } \\
\text { D }\end{array}$ & $450-900 \mathrm{~nm}$ & $\begin{array}{l}\text { Pan - } 65 \mathrm{~cm} \text { MS - } 2.62 \text { (Nadir) } \\
\text { Pan - } 73 \mathrm{~cm} \text { MS - } 2.90 \text { (off } \\
\text { Nadir) }\end{array}$ & 5 Bands & 1-3.5 Days & $\begin{array}{l}16.8 \mathrm{~km} \\
18 \mathrm{~km} \text { (Early 2013) }\end{array}$ & USA & 18 Oct 2001 \\
\hline $\begin{array}{l}2 \\
0\end{array}$ & IKONOS & $0.45-0.90 \mu \mathrm{m}$ & $\begin{array}{l}\text { Pan - 0.82 MS - } 3.28 \text { (at Nadir) } \\
\text { Pan - 1.0 MS - } 4.0 \text { (off Nadir) }\end{array}$ & 5 Bands & Approx. 3 Days & $\begin{array}{l}11.3 \mathrm{~km} \text { (Nadir) } \\
11.8 \mathrm{~km} \text { (off-Nadir) }\end{array}$ & USA & 24 Sept 1999 \\
\hline
\end{tabular}

138

139

140

\begin{tabular}{|c|c|c|c|}
\hline & Sensors & Platform & Spectral range (resolution) \\
\hline 01 & Hyperion & EO-1 & $400-2500 \mathrm{~nm}$ \\
\hline 02 & CHRIS & PROBA & $400-1050 \mathrm{~nm}$ \\
\hline 03 & EnMap & & $\begin{array}{l}420-2450 \mathrm{~nm} \\
\sim \text { VNIR }(420-1000 \mathrm{~nm}) \\
\sim \text { SWIR I }(900-1390 \mathrm{~nm}) \\
\sim \text { SWIR II }(1480-1760 \mathrm{~nm}) \\
\sim \text { SWIR III }(1950-2450 \mathrm{~nm})\end{array}$ \\
\hline 04 & HyspIRI\# & & $\begin{array}{l}\begin{array}{l}\text { optical hyperspectral } \\
\text { imaging } \sim 400-2500 ~ \mathrm{~nm} \\
\text { and }\end{array} \\
\text { Multispectral IR at 8-12 } \mu \mathrm{m}\end{array}$ \\
\hline 05 & HySIS & & $400-1200 \mathrm{~nm}$ \\
\hline 06 & SHALOM & MBT SPACE & $400-2500 \mathrm{~nm}$ \\
\hline 07 & PRISMA & $\begin{array}{ll}\text { VEGA } & \text { Italian } \\
\text { launcher. } & \end{array}$ & $400-2500 \mathrm{~nm} /$ \\
\hline 08 & $\begin{array}{l}\text { FLEX } \\
\text { (Fluorescence } \\
\text { Explorer) }\end{array}$ & Earth Explorer & \\
\hline 09 & HySI & Chandrayaan-1 & $\begin{array}{l}400-950 \mathrm{~nm} \\
(15 \mathrm{~nm})\end{array}$ \\
\hline
\end{tabular}

\begin{tabular}{|c|c|c|c|c|}
\hline Spatial /Spectral resolution & Channels & Revisit time & $\begin{array}{l}\text { Organization } \\
\text { /Nation }\end{array}$ & Launch year \\
\hline $30 \mathrm{~m}$ & 220 & 200 days & NASA & Nov 2000 \\
\hline $\begin{array}{l}\mathbf{1 8} \mathrm{m} \text { to } 36 \mathrm{~m} \\
\text { - } \mathbf{6 3} \text { spectral to provide } 34 \mathrm{~m}\end{array}$ & 150 & 2 (mid-latitudes) & ESA & 22 Oct 2001 \\
\hline $\begin{array}{l}30 \mathrm{~m} \text { at Nadir } \\
\text { Spectral Sampling } \\
\text { VNIR: } 5-10 \mathrm{~nm} \text { (6.5 } \mathrm{nm} \text { average) } \\
\text { SWIR: } 10 \mathrm{~nm} \text { (average) }\end{array}$ & 232 & $\begin{array}{l}23 \text { days \& } \\
4 \text { days (across track } \\
\left. \pm 30^{\circ}\right)\end{array}$ & DLR Germany & 2015 \\
\hline $\begin{array}{l}60 \mathrm{~m} \text { at } 150 \mathrm{~km} \text { Swath } \\
\text { (after } 2013-30 \mathrm{~m} \text { ) }\end{array}$ & 217 & $\begin{array}{l}\text { VSWIR-19 Days } \\
\text { (after 2013- } 16 \text { days) } \\
\text { TIR -5 days }^{@} \\
\end{array}$ & NASA & 2015 \\
\hline $30 \mathrm{~m} / 10 \mathrm{~nm}$ & 55 & 5 / 19 days & ISRO India & November 2018 \\
\hline $10 \mathrm{~m}$ & 241 & 2 days & $\begin{array}{ll}\text { Israel } & \text { Space } \\
\text { Agency } & \end{array}$ & 16 June 2019* \\
\hline $20-30 \mathrm{~m}$ & 237 & 29 days & $\begin{array}{ll}\text { Italy } & \text { Space } \\
\text { agency } & \end{array}$ & 23 March 2019* \\
\hline $300 \mathrm{~m}$ & & 28 days & ESA & $2022 *$ \\
\hline $30 \mathrm{~m}$ & 64 & & ISRO India & 2008 \\
\hline
\end{tabular}




\begin{tabular}{|c|c|c|c|c|c|c|c|c|}
\hline \multirow[t]{4}{*}{10} & \multirow[t]{2}{*}{$\mathrm{HJ}-1 \mathrm{~A} /$} & \multirow[t]{4}{*}{ CAST } & WVC-0.43-0.90 $\mu \mathrm{m}$ & $30 \mathrm{~m}$ & 4 & 4 days & \multirow[t]{4}{*}{ China } & \multirow[t]{4}{*}{ September 2008} \\
\hline & & & HSI-0.45 - $0.95 \mu \mathrm{m}$ & $100 \mathrm{~m}$ & 115 & $\begin{array}{l}\text { 4-31 days(side looking } \\
\left. \pm 30^{\circ}\right)\end{array}$ & & \\
\hline & \multirow[t]{2}{*}{ HJ-1B } & & WVC 0.43-0.90 $\mu \mathrm{m}$ & $30 \mathrm{~m}$ & 4 & 4 days & & \\
\hline & & & $\begin{array}{r}\text { IRMSS 0.75-1.10 } \mu \mathrm{m} \\
1.55-1.75 \mu \mathrm{m} \\
3.50-3.90 \mu \mathrm{m} \\
10.5-12.5 \mu \mathrm{m}\end{array}$ & $\begin{array}{l}150 \mathrm{~m} \\
150 \mathrm{~m} \\
150 \mathrm{~m} \\
300 \mathrm{~m}\end{array}$ & 4 & 4 days & & \\
\hline 11 & Hero(CASI) & & $400-2500 \mathrm{~nm}$ & $30 \mathrm{~m}$ & $>200$ & 3 & & \\
\hline 12 & VENUS & & $415-910 \mathrm{~nm}$ & $5.3 \mathrm{~m}$ & 12 & 2 & CNES/ Israel & 2016 \\
\hline 13 & $\begin{array}{l}\text { SumbandilaSat/ } \\
\text { MSI }\end{array}$ & & $440-2350 \mathrm{~nm}$ & $15 \mathrm{~m} /$ & 200 & - & South Africa & 17 Sep 2009 \\
\hline
\end{tabular}

$141 *$ Wide View CCD Cameras (WVC)

142 Hyperspectral Imager (HSI)

143 Infrared Multispectral Scanner (IRMSS)

144

145 \#- https://hyspiri.jpl.nasa.gov/downloads/reports_whitepapers/HyspIRI_FINAL_Report_1October2018_20181005a.pdf

146 @- TIR measures both day and night data with 1 daytime image and 1 night-time image every 5 days 


\subsection{LULC mapping approaches and products}

\section{$149 \quad$ 1.3.1 LULC mapping from conventional to remote sensing methods}

150 The conventional methods like ground truthing, surveying, etc., that employ field surveys and on site human-made observations, are generally reliable methods of mapping, however, they are considered as time consuming and expensive methods (Koutsias et al. 1999; Bai et al. (2017); Lamine et al. 2019) During the pre-remote sensing era, LULC mapping, forest inventory and LULC changes were based upon these traditional methods. The use of conventional sources has been replaced with remotely sensed data for more accuracy, cost effective, time efficient and more coverage of the area for mapping and change analysis. Moreover, remotely sensed data can be stored in a digital format that can be transferred easily, taken to another place, or by a person for analysis as compared to conventional paper survey records. Therefore, remotely sensed datasets were in use and proved more fruitful, economic, easier, convenient, and storage capability for a longer time utilised all around for LULC mapping and assessment.

Data integration of remote sensing and GIS was in use for LULC classification. GIS data including census data, topography, GPS points were combined with remote sensing images for LULC classification. Manual digitization within a GIS environment was a way of LULC classification and mapping based on image interpretation using elements of image interpretation like size, shape, shadow, tone, pattern, texture, association, colour etc. (Lillesand et al. 2014). Thus, LULC classification required interpretation of the different features which was needed to be recognized with remotely sensed images.

\subsubsection{LULC Operational Products}

Several land cover classification systems and maps have been developed by national and international agencies. Examples of those include the Global Land Cover Characteristics Database (USGS), CORINE by EEA (European Environmental Agency), GLC2000 (European Commission's Joint Research Centres), and the GeoBase (Canadian Council on Geomatics and Natural Resources) (Johnson and Singh 2003). Most of these land cover maps were hierarchical in nature and reviewed by reputed international agencies such as USGS (Anderson 1976), Food and Agriculture Organisation (Di Gregorio 2005) and EEA. These maps are unsupervised classification GLC2000 generated at 1 $\mathrm{km}$ spatial resolution (Bartholomé and Belward 2005), GlobCover at $300 \mathrm{~m}$ spatial resolution (Arino et al. 2008), supervised MODIS land cover types at 500m spatial resolution (Friedl et al. 2002; Friedl et al. 2010) and Coordination of Information on the Environment Land Cover (CORINE) represented as a cartographic product, at a scale of 1:100 000 (ESA 2017). Additionally, these regional maps were generated with the help of remotely sensed data including AVHRR (Loveland et al. 2000), MODIS (Friedl et al. 2002), Landsat (Tucker et al. 2004), SAR data (Balzter et al. 2015; Cole et al. 2018) and SPOT (Bartholomé and Belward 2005). Evidently, to obtain more out of these maps, there is a need for regular update of such land cover maps, which can easily provide changes for some period, easy for management and planners to take appropriate actions.

\section{Characteristics of the satellite data}

\section{$188 \quad 2.1 \quad$ Optical}

\subsubsection{Spatial dimension}


190 Optical remote sensing has served as pioneer remote sensing data set along with traditional field 191 surveys. Researchers and scientists started working with Landsat MSS data having an original spatial 192 resolution of $80 \mathrm{~m}$ (thermal band $6-120 \mathrm{~m}$ and later on TM has $60 \mathrm{~m}$ ) to classify land use and land 193 cover, which continuously increased to $30 \mathrm{~m} \mathrm{TM} / \mathrm{ETM}+$ and $15 \mathrm{~m}$ (for the panchromatic band). It is, 194 therefore, the major data source for LULC mapping from small to large scale at the global level. With 195 the recent advancement in the space-borne missions, advanced remote sensing imageries with higher 196 spatial resolution are used that achieve higher accuracies nowadays. Several researchers have worked 197 with Landsat-TM, ETM+ for LULC mapping and demonstrated good accuracy results, which was 198 further enhanced with the incorporation of sensors followed by SPOT, LISS III, LISS IV, WORLD 199 VIEW- 1, WorldView-2. Once, initiated with low spatial resolution around $80 \mathrm{~m}$, the move has 200 achieved the spatial resolution of $1 \mathrm{~m}$ or $0.6 \mathrm{~m}$ for better results (Salehi et al. 2013).

201 The high spatial resolution of the satellite images allows spatial enhancement techniques to be applied 202 in the satellite data that result in better accuracy while the use of textural properties can increase the 203 accuracy of LULC mapping since new information by considering spatial patterns in the data is taken 204 into account in the classification process (Mallinis and Koutsias 2008; Koutsias 2010). Additionally, 205 the high spatial resolution enhanced the idea of applying segmentation techniques to extract textural 206 properties being added into classification process that significantly improve the results. Thus, object207 based techniques become popular and perform better that pixel-based when classifying LULC 208 especially when high spatial resolution data are used (Blaschke 2010).

209 Additional advanced methods were employed for mapping and analysis using classifiers with high 210 spatial resolution images (Salehi et al. 2013), as for instance advanced wavelet-based techniques of 211 pixel- and object-based approaches for three different very high spatial resolution images, such as 212 images from sensors like WorldView-2, QuickBird, and Ikonos. The main purpose of using this 213 technique is that it preserves the nature of the original spectral and spatial signatures. Results of those 214 studies were often significantly increased as compared to the use of only the original bands of the 215 images, demonstrated that enhanced results were contributed mainly from spectral features of objects 216 as compared to spatial features (Kavzoglu Taskin et al. 2015; Chatziantoniou et al. 2017).

217 On the other, usually very high spatial resolution satellite data lack high spectral resolution. In such 218 cases there are techniques that have been applied for data merging or data fusion, therefore the final 219 data is a combination of high spatial and high spectral resolution and combine both data 220 characteristics. Such cases include various types of datasets like- optical with optical for a different resolution, optical with hyperspectral, optical with LiDAR, optical with Radar, hyperspectral with radar, hyperspectral with LiDAR, a fusion of remote sensing data with GIS etc. All these enhance the information that was utilized for land cover mapping with ease and accuracy than individual data. Table 3 illustrate the several combinations of remote sensing datasets used for the LULC and change analysis, including traditional aerial colour photos, multi-sensor, multi-temporal, multi-resolution datasets. 
Table-3: Different Remotely sensing data sources integration for LULC.

\begin{tabular}{|c|c|c|c|}
\hline Sl & Data types & Categories & References (but not limited to) \\
\hline 1 & Remote sensing + GIS data & $\begin{array}{l}\text { RS data with ancillary datasets- such as topography, } \\
\text { census, GPS, field data, cartographic integration }\end{array}$ & (Rogan et al. 2003; Na et al. 2010) \\
\hline \multirow[t]{3}{*}{2} & \multirow{3}{*}{$\begin{array}{lr}\text { High } & \text { Spatial/spectral } \\
\text { resolution imagery- individual } \\
\text { data } \quad \text {-multispectral, } \\
\text { hyperspectral, SAR }\end{array}$} & Multispectral & $\begin{array}{l}\text { (Kanellopoulos et al. 1992; Lee and Lathrop 2006; Tan KC et al. 2010; } \\
\text { Salehi et al. 2013; Singh S et al. 2018) }\end{array}$ \\
\hline & & Hyperspectral & $\begin{array}{l}\text { (Thenkabail et al. 2004; Pal 2006; Tan Q and Wang 2007; Liu and Li } \\
\text { 2013; Hegde et al. 2014; Vijayan et al. 2014; Pandey et al. 2018) }\end{array}$ \\
\hline & & SAR & $\begin{array}{l}\text { (Henderson F 1975; Henderson FM and Xia 1997; Saatchi et al. 2000; } \\
\text { Simard et al. 2000; da Costa Freitas et al. 2008; Werner et al. 2014; } \\
\text { Clerici et al. 2017; Hagensieker et al. 2017; Spies et al. 2017) }\end{array}$ \\
\hline 3 & Multi-Temporal datasets & Different time-period data & $\begin{array}{l}\text { (Roberts et al. 2002; Engdahl and Hyyppa 2003; Rogan et al. 2003; } \\
\text { Budreski et al. 2007; Pandey et al. 2012; Pandey et al. 2013; Sexton et } \\
\text { al. 2013; Campbell et al. 2015; Feng et al. 2015; Bai et al. 2017) }\end{array}$ \\
\hline 4 & Multi-Resolution fusion & Low resolution multispectral+ high resolution PAN & (Pandey et al. 2012; Sharma et al. 2012) \\
\hline 5 & Multi-Source & Similar data from different sensors & $\begin{array}{l}\text { (Solberg et al. 1996; Engdahl and Hyyppa 2003; Thenkabail et al. } \\
\text { 2004; Budreski et al. 2007; Evans et al. 2010; Noor et al. 2011) }\end{array}$ \\
\hline \multirow[t]{5}{*}{6} & \multirow[t]{5}{*}{ Multi-Sensor and fusion } & Optical + Ancillary data or Optical & $\begin{array}{l}\text { (Serpico and Roli 1995; Rogan et al. 2003; Platt and Goetz 2004; } \\
\text { Karathanassi et al. 2007) }\end{array}$ \\
\hline & & Optical + Radar & $\begin{array}{l}\text { (Solberg et al. 1996; Simard et al. 2000; Amarsaikhan et al. 2007; } \\
\text { Amarsaikhan et al. 2010; Zhu et al. 2012; Brown et al. 2018; Cass et } \\
\text { al. 2019) }\end{array}$ \\
\hline & & 3. $\quad$ Optical + Hyperspectral & (Noor et al. 2011; Vijayan et al. 2014; Lamine et al. 2019) \\
\hline & & $\begin{array}{l}\text { 4. Multispectral/Hyperspectral/Spectroscopy } \\
+ \text { LiDAR }\end{array}$ & $\begin{array}{l}\text { (Haack et al. 2000; Koetz et al. 2008; Cook et al. 2009; Gong et al. } \\
\text { 2011; Yan et al. 2015) }\end{array}$ \\
\hline & & $\begin{array}{l}\text { 5. } \\
\text { data (SRTM) }\end{array}$ & $\begin{array}{l}\text { (Evans et al. 2010; Balzter et al. 2015; Chatziantoniou et al. 2017; } \\
\text { Clerici et al. 2017; Gibril et al. 2017; Brown et al. 2018; Colson et al. } \\
\text { 2018; Kaplan and Avdan 2018) }\end{array}$ \\
\hline 7 & Different data borne fusion & $\begin{array}{l}\text { Aerial photographs + RS data like aerial colour } \\
\text { photographs }\end{array}$ & (Park et al. 2001) \\
\hline
\end{tabular}




\subsubsection{Spectral dimension}

230 Optical multispectral remote sensing has been used for LULC classification, mapping, and assessing their changes on local to regional scales due to high spatial resolution (high up to $0.61 \mathrm{~m}$ refer table 1). However, their use has low visual interpretation and the classification scheme employs few land cover types due to difficulty in interpreting a large number of features because of the limited spectral information. Their low/medium spatial resolution is an additional obstacle since such data lack the ability to provide detailed spatial information that many times is needed at sub-pixel level. Although optical multispectral images have high spatial resolution but they are unable to identify different feature in the similar group (Kumar et al. 2015). Therefore, they does not provide detailed LULC mapping and classification across any classification algorithm due to low spectral resolution that hurdle accurate species identification. However, to differentiate different feature such as soil and plant species, incorporation of hyperspectral remote sensing approach were introduced in LULC domain (Thenkabail and Lyon 2016) to accurately identify different features using unique spectral information (St-Louis et al. 2009; Kumar et al. 2015), attributed to their unique signature due to chemical and physical properties (Gould 2000; Gillespie et al. 2008; Palmer et al. 2008). For example, in plants, they differ due to pigments, structure and water content (Kalacska et al. 2007; White et al. 2010; Kumar et al. 2015; Thenkabail and Lyon 2016; Pandey et al. 2019) and soil have different spectral signature due to variation in iron oxides, organic matter, clays, calcite, hygroscopic water (Ben-Dor Eyal and Banin 1995; Ben-Dor E et al. 1999; Ben-Dor E 2002; Stevens et al. 2008; Nocita et al. 2015). Thus, advancement in the spectral resolution has enabled researchers to discriminate and identify different land cover features using spectral resolution with enhanced accuracy as compared to multispectral data (St-Louis et al. 2009).

Borak et al. (2000) presented the importance of temporal metrics for LULC analysis. They performed several temporal change metrics to analyse the land cover changes while utilised a combination of remotely sensed data with spatial metrics for similar analysis. Therefore, an appropriate set of variables for measuring and characterizing LULC is needed in terms of spatial, spectral or temporal dimension that play an important role providing milestones in the analysis of land cover. Adar et al. (2014) utilised multispectral and hyperspectral images (HyMap) acquired at two or more different times to detect spatial, spectral and temporal changes. Adar et al. (2014) also demonstrated that the incorporation of spatial-spectral domains threshold has better change detection capabilities and reduce false alarm than the use of spectral domains only which has high detection capabilities with moderate alarm. To overcome the low spectral and spatial resolution, hyperspectral imaging systems have been developed that can detect subtle changes in the spectral ranges, and thus discriminate between vegetation types, crops and other features during LULC classification (Pandey et al. 2018).

\subsubsection{Spatial versus spectral dimension}

Spatial and spectral resolution are significant factors in the assessment of overall mapping accuracy while the temporal resolution is significant in evaluating change mapping. The spatial dimension provides the features extent while the spectral dimension provides subtle changes in the features and thus it is contributing as an important part of LULC mapping and classification. Since spectral characteristics provide more information about the features, hyperspectral imagery has more power to map LULC as compared to multispectral imagery. Thenkabail et al. (2004) illustrated the power and better mapping accuracy of hyperspectral data (Hyperion) over multispectral data (Landsat ETM+, IKONOS, ALI). 
Though spectral information forms the basis of hyperspectral remote sensing image classification and interpretation (Liu and Li 2013), the spectral information alone is not useful for the classification and mapping as demonstrated by Bai et al. (2017). To enhance and provide better outcome results, other parameters were incorporated along with the spectral information. Therefore, Liu and Li (2013) came out an idea to employ the textural feature with spectral information in order to achieve more accuracy. Textural properties were constructed using wavelet transformation techniques creating coefficient matrices. They employed Artificial Neural Network (ANN) algorithms to the textural applied images for the mapping purposes and they illustrated the better classification results.

Although Landsat images are capable of land cover mapping and assessing change dynamics, high spatial resolution images such as QuickBird, Cartosat, IKONOS provide detailed feature analysis and more accurate overall results as compared to Landsat series (TM, MSS, ETM+). Further, this is also a matter of mapping spatial scale and of the features of the land cover/use to be mapped. While, the use of hyperspectral images has overcome the inability of multispectral images to differentiate the different types within same features (crop types, plant types), and therefore, hyperspectral images have been in use for mapping and change analysis though it is expensive in case of airborne images. Availability of temporal datasets of space-borne hyperspectral Hyperion data is possible as compared to airborne hyperspectral images, which allow significant research to enable LULC mapping and monitoring of specific regions easily. The move from spatial and spectral to other datasets, basically move around the structural properties, elevation information and other properties (such as intensity, texture, interferometry). These properties are added benefit when combined with basic dimensions during image analysis.

\subsection{Active sensing systems}

\subsubsection{Synthetic Aperture Radar (SAR)}

SAR applications for landscape change and pattern analysis has received less attention as compared to optical remote sensing, due to the high variability of the landscape, complexities in the interaction between radar signals and human built-up environment (Henderson FM and Xia 1997). The usability of optical satellite data in LULC classification is severely limited by cloud cover in many parts of the world (Cass et al. 2019). The ability of SAR systems to image throughout day and night whilst remaining immune to the issue of cloud cover can fill such information gaps during overcast periods, and therefore allow for reliable mapping. SAR can penetrate cloud cover, but the potential of C-band single polarization intensity images is limited. The advantage of SAR data over optical or hyperspectral data is its sensitivity to structural features of the terrain, making LULC simpler and easier to interpret the different classes. Interferometric SAR (InSAR) can provide complementary information to the backscattered intensity in the form of interferometric coherence (Colson et al.

308 2018; Whyte et al. 2018).

309 During the past decades, several radar sensors, e.g. SIR-A, SIR-B, SIR-C/X, ERS-1/2, JERS-1, and

310 RADARSAT, have been used for different applications and for LULC mapping due to their ability to 311 provide unique information about the characteristics of landscapes (Chatziantoniou et al. 2017). The 312 higher resolution Radarsat-2 instrument (also C-band) has been used alone in grassland studies and 313 has been shown to provide a good separation of crops and improved grasslands through use of quad314 pol (HH, HV, VV, VH) data (Buckley and Smith 2010). Several studies were carried out using SAR images, including recent studies focusing on Sentinel-1 use, to map land covers (Brown et al. 2018). For example, Zhu et al. (2012) assessed urban land cover using Landsat and SAR data for its 
317 effectiveness to map 17 different cover types considering spectral, temporal and spatial dimensions.

318 The authors used multi-seasonal Landsat data with single season Advanced Land Observing Satellite -

319 Phased Array Type L-band Synthetic Aperture Radar (ALOS-PALSAR) data combination for above

320 purpose. The results were demonstrated with the contribution of different dimensions such as textural

321 variables derived from Landsat/PALSAR and multi-seasonal Landsat data and integrated datasets of

322 both input sensors against the individual data results. PALSAR data generated accuracy of $31 \%$

323 approx. while the accuracy was improved with the addition of a textural variable derived from

324 PALSAR data to about $\sim 73 \%$. Landsat data produced mapping accuracy of $\sim 78 \%$ while the addition

325 of multi-seasonal images results in enhanced accuracy up to $\sim 87 \%$ and the inclusion of textural

326 variables derived from Landsat images resulted in an even higher accuracy of $\sim 92.69 \%$.

327 (Ling et al. 2012, 2013)was able to produce a forest and non-forest classification with accuracy in 328 excess of $80 \%$ using multi-temporal alternating polarization ( $\mathrm{HH}, \mathrm{HV}$ ) data. Another study using the same data (Thiel et al., 2009) further demonstrated the high accuracy that can be achieved with ASAR data in the production of a basic land cover classification. Additionally, the higher resolution Radarsat-2 instrument (also C-band) has been used alone in grassland studies and has been shown to provide a good separation of crops and improved grasslands through use of quad-pol (HH, HV, VV, 333 VH) data.

334 New EO satellites, especially optical and RADAR, such as the instruments included in the Sentinel platforms, offer greater resolutions, both spectrally and spatially, than previously available openaccess information. For example, recently Whyte et al (2018) examined the synergistic use of Sentinel-1 and 2 combined with the SAGA Wetness Index for wetland LCLU mapping. In the same study, authors developed a new object-based image analysis technique for mapping LULC with emphasis specifically in their study on wetlands. They compared results from their method against two powerful machine learning techniques, namely Support Vector Machines (SVMs) and Random Forests (RFs) for a region in South Africa. Their results showed that a combination with Sentinel-1 and 2 synergies can successfully produce a LULC classification.

A combination of EO data provided essential information of different dimensions for mapping thus resulting in accurate results derived from spectral, spatial, temporal dimensions. Spatial dimension changes are analysed moving from lower to higher spatial dimensions, and spectral dimension changes from high spectral resolution keeping the spatial regions as change and no change pixels similar at significantly less time (Adar et al. 2014). The multi-temporal analysis is assessed using spatial/spectral combination over duration of the time-period for the particular regions. Thus, using biophysical parameters, geophysical parameter, terrain, backscatter, textural and structural measurements in combination with the use of ancillary data such as elevation, a climate were incorporated for mapping with SAR in different research. These parameters were used successfully, while physical parameter and interferometry use for LULC mapping were given by Deng et al. (2015) who used RADARSAT-2 polarimetric SAR (PolSAR) data to develop four component algorithms for LULC classification. Four components namely; polarimetric decomposition (selected physical scattering parameters), PolSAR interferometry (interferometric information), object-oriented image analysis (extracting textural and spatial features from image objects), and decision tree algorithms (select features and implementation) are employed to generate LULC classification. The authors illustrated an improvement in LULC classification results over existing the Wishart supervised classification scheme, increase in overall accuracy from $70 \%$ to $87 \%$ and kappa values from 0.65 to 0.84 respectively. example spatial), hyperspectral (spectral) as well as radar (for example texture) remote sensing for 
land use analysis and classification using different algorithms (Miettinen and Liew 2011; Hansen et al. 2013; Jin et al. 2014; Gómez et al. 2016). Each remote sensing data deliver complementary and additional information in term of spatial, spectral or textural, hence LULC classification and mapping can exploit the combination of the two or more information types to deliver the enhanced precision mapping results, using fusion techniques. (Bagan et al. 2012). For example, Erasmi and Twele (2009) have illustrated the improvement in the classification and mapping when incorporated the SAR based texture information (derived from Envisat ASAR data) with Visible-NIR multispectral information from Landsat ETM+ data. Similarly, Qin et al. (2016) exemplified the fusion robustness with ALOS PALSAR (reducing the limitations of frequent cloud coverage and improved feature separation) and phenological information from the MODIS sensor to map forest employing decision tree algorithm. Gessner et al. (2015) combined three remotely sensed data sets, namely optical MODIS, Envisat ASAR and TandemX/TerraSAR-X radar data for mapping using random forest algorithm. In order to exploit the properties of individual data such as texture, backscattering amplitudes, Breiman (2001) employed an unsupervised classification algorithm for mapping purposes.

\subsubsection{Light Detection And Ranging (LiDAR)}

LiDAR can have many advantages over other datasets; mainly it can overcome the cloud obstacle and can provide more information as compared to the multi-hyperspectral datasets. LiDAR data can provide information about the elevation of the landscape, thus help in contributing towards better mapping using elevation and height derived products. Previous studies illustrate that LiDAR data has been implemented for LULC mapping successfully (Antonarakis et al. 2008). Charaniya et al. (2004) attempted LiDAR based classifications using LiDAR point cloud elevation and intensity data to classify roofs, grass, trees and roads. Bartels and Wei (2006) performed LiDAR based maximum likelihood classifications fused with co-registered spectral bands achieving accurate results. Brennan and Webster (2006) classified LiDAR derived products such as DSM, DEM, and intensity with 94 to $98 \%$ for seven classes, demonstrating the accurate generation of LULC. The techniques used in above study include image object segmentation and rule based techniques which harness the spectral and spatial attributes of the LiDAR datasets. Whereas Antonarakis et al. (2008) used intensity and elevation only for classification of land use land cover and demonstrated overall classification accuracies of $95 \%$ and $94 \%$ for the methods including and excluding the ground influence respectively. These results show that LiDAR can provide better overall results as compared to other remotely sensed images.

In order to test the capabilities and robustness of integration, several remotely sensed datasets were integrated with LiDAR data using different approaches for LULC mapping studies. Some of them are listed, for example, LiDAR integration with high spatial resolution images such as QuickBird (Chen Y et al. 2009) and World-View (Minh and Hien 2011; Kim and Kim 2014) and even with low spatial resolution images Landsat TM (Singh Prafull et al. 2011). Further, multi-sensors and multi-source remotely sensed images require downscaling process to match the spatial resolution between the all employed images. (Singh KK et al. 2012)assessed the best resolution (1 m, $5 \mathrm{~m}, 10 \mathrm{~m}$ and 30m) for LiDAR-Landsat TM fused data, after downscaling Landsat TM for LULC mapping integrated with airborne LiDAR data. To show the capabilities of LiDAR integration with other datasets, the authors compared the accuracy rate of three different classified maps with Landsat TM at $30 \mathrm{~m}$, LiDAR data and LiDAR-Landsat TM fused data using supervised MLC and classification tree methods. Resultant output conferred the robustness of data integration for enhanced results for fused LiDAR-Landsat TM 
data using all surface models (structural and intensity) which increased accuracy by 32\% as compared to $1 \mathrm{~m} \mathrm{LiDAR}$ and by $8 \%$ over TM individually (Singh KK et al. 2012). While this study shows the advantages of LiDAR data for mapping, it also shows that $1 \mathrm{~m}$ LiDAR data is not capable of accuracy in results, as its accuracy is less than Landsat TM.

412 LIDAR and SAR can provide structural, textural, physical, biophysical, backscatter information, interferometry for mapping where sometimes these parameters play an important role in mapping for better accuracy. When LiDAR data is combined with high spatial resolution images other than Landsat images such as IKONOS, World-View, Quick Bird, the accuracy results increases and has better mapping accuracy than low spatial resolution combined datasets (Cook et al. 2009; Gong et al. 2011). (Gong et al. 2011)using high spatial resolution QuickBird and LiDAR derived products (only height information) together at one site while HyMap hyperspectral imagery at another site, with a decision tree and ANN, were employed to compare with newly developed OPTINC model (optimized immune network-based classification model).

\subsection{LULC using multi-sensors, source datasets- a combination of spatial, spectral dimension and other parameters}

424 Data fusion techniques, including many possible combinations of data integration as illustrated in 425 Table 3, have added advantages of utilizing characteristics of individual datasets together. Data fusion enhances the information and the composite images are visually more interpretable and better for being used for LULC mapping and achieve higher accuracy than individual data. Fusion of data set includes remote sensing data with GIS, multi-sensor data (different remote sensing data like optical, hyperspectral, LiDAR, SAR) or multi-temporal data (different time-period) (see Table 3). Data integration can be carried out at four different levels; namely signal level, pixel level, feature level and decision level. The level of integration depends upon the data acquisition and the purpose of the study.

433 Unlike single source data, multi-source, multi-sensor data integration offers advanced and better potential for interpretation and discrimination between different features of land cover types easily and effectively (Chatziantoniou et al. 2017; Chen B et al. 2017). There are several studies based on data integration and its potential to discriminate features with good results as compared to individual data (Pohl and Van Genderen 1998; Amarsaikhan et al. 2007; Kaplan and Avdan 2018). Data integration generates new composite image which delivers better-enhanced spatial and spectral information (Shen 1990; Pohl and Van Genderen 1998; Karathanassi et al. 2007; Dong et al. 2009), hence provide more information and achieves improved results for decision making (Hall and McMullen 2004). Additionally, data integration provides numerous benefits according to user needs and requirements, such as image sharpening, helps in geometric corrections, adding information, provide detailed feature information, add missing information, provide stereo-viewing capabilities, discriminate the feature with enhancement easily which is not visible in either of the image individually (Pohl and Van Genderen 1998). Thus, most common uses of fusion techniques are to enhance the image quality and to sharpen visualisation of the image. Therefore, image fusion improves the capabilities and performance of data and enhances the image interpretation and evaluation capability better than individual data alone (Pohl and Van Genderen 1998; Karathanassi et al. 2007). Furthermore, data integration detects small changes using multi-temporal data as compared to individual data alone (Shen 1990; Pohl and Van Genderen 1998; Park et al. 2001; Karathanassi et 

comparative study on remote sensing fusion methods)

Multispectral-hyperspectral data and LiDAR data have been fused together for combining their spatial-spectral and geometric characteristic together in LULC mapping. For example, Amarsaikhan et al. (2010) used multi-source and multi-temporal data to enhance the urban land cover features using different data integration techniques and demonstrated the better accuracy with the combined images of QuickBird image (2006) and a TerraSAR-X image (2008). In another study, Yan et al. (2015) used LiDAR derived height, intensity, waveform and the combination of multi-sensors remotely sensed data to assess LULC mapping and change dynamic and presented the usefulness of data integration.

While integration of multi-hyperspectral was common, some authors combined LiDAR, SAR with hyperspectral for LULC mapping to extract the textural, intensity and structural features together for the mapping. For instance, Haack et al. (2000) combined hyperspectral and LiDAR data for analysing LULC classification. They utilized multi-sensor data in their study for LULC mapping with the help of ground control points. Spectral information from the hyperspectral sensor was used for signature classification of LULC with statistical decision rule for feature classification. Even hyperspectral/multispectral have been combined with SAR data for mapping, by merging the spectral information from multi-hyperspectral data and textural, intensity information from SAR data (Amarsaikhan et al. 2007; Amarsaikhan et al. 2010; Zhu et al. 2012). Different manipulations of radar data have been applied for obtaining results which include texture, spatial filtering and despeckling. Hence, from above discussion it can be concluded that multi-source, multi-sensors, multi-temporal information can significantly enhance the visual interpretation and provide improved results over the individual dataset.

\section{Selection of appropriate classifiers}

Several studies reveal that classification capability of remotely sensed data depends upon the types of input data used in the study along with landscape complexity. For example, Mallinis and Koutsias (2012) observed that the variance in the accuracy results imposed by the different methods applied was less than that imposed by factors differentiated locally in the three test sites they used. This section of the present review focuses on the importance of selection of appropriate classifiers for LULC mapping. This section elaborates different classifier techniques and presents their advantages and disadvantages for LULC mapping along with robustness of one over the other technique.

482 Many research works have been carried out to explore the robustness and achievements of classifiers for different remotely sensed datasets and their accuracy results. Yet, to define the most appropriate classifier for mapping is still in question. The most popular classifier algorithms include supervised classifiers [Maximum Likelihood Classifier (MLC), Spectral Angle Mapper (SAM), Support vector Machine (SVM), Random Forest (RF), Decision Tree (DT), Minimum Distance (MD) etc.] and unsupervised classifiers ( $k$-means and ISODATA), further, these can be categorised into pixel-based (MLC, SVM) and object-based methods. Though pixel-based methods mainly focus on the independence of pixels in the classification, they have certain limits for mixed feature classification, while object-based methods employ the incorporation of neighbourhood pixels for spectral as well as spatial characteristics. MLC is one of the widely used classifier techniques for multispectral images, whereas SAM is used mainly for hyperspectral images using the spectral signature of the target features for classification outcome. Therefore, SAM often results in low accuracy due to the incorporation of only the spectral information available during classification analysis resulting in unclassified pixels in the test sites. Therefore, there is a requirement to employ the spatial information together with spectral information and exploit as much as possible information for accurate 
classification results. Thus, employment of spatial-spectral information has resulted to more accurate and reliable classification results as compared to their individual use. This has been demonstrated by several researchers (Rajadell et al. 2009; Tarabalka et al. 2010; Huang X and Zhang 2011; Fauvel et al. 2012; Paneque-Gálvez et al. 2013), thereby, illustrated the utilisation of integrated spectral-spatial information in hyperspectral imagery improves the classification results compared with the individual characteristics implementation. While the spatial-spectral information was being employed, the neighbouring pixels were extracted employing the morphological (Fauvel et al. 2008) or fixed-size window techniques (Camps-Valls and Bruzzone 2005). Petropoulos et al. (2012) concluded that SVMs algorithm (OA- 89.26 and Kappa- 0.88) outperform ANN (OA- 85.95 and Kappa- 0.842) in terms of overall accuracy and individual users accuracy as shown in Figure 3. While in the Mediterranean setting, a comparison with Object based classifier with SVMs classifier, object-based algorithm (OA- 81.33 and kappa- 0.779) has outperformed pixel-based classifier such as SVMs (OA76.23 and kappa- 0.719). But this is true in case when good segmentation results have been obtained (Conchedda et al. 2008). In early studies on these methods, spectral information from the neighbourhoods was extracted by either a fixed-size window (Camps-Valls and Bruzzone 2005) or morphological profiles (Fauvel et al. 2008) and was used for classifying and labelling image pixels. (See Srivastava et al. (2012) for a comprehensive knowledge on classification algorithm selection for LULC mapping)
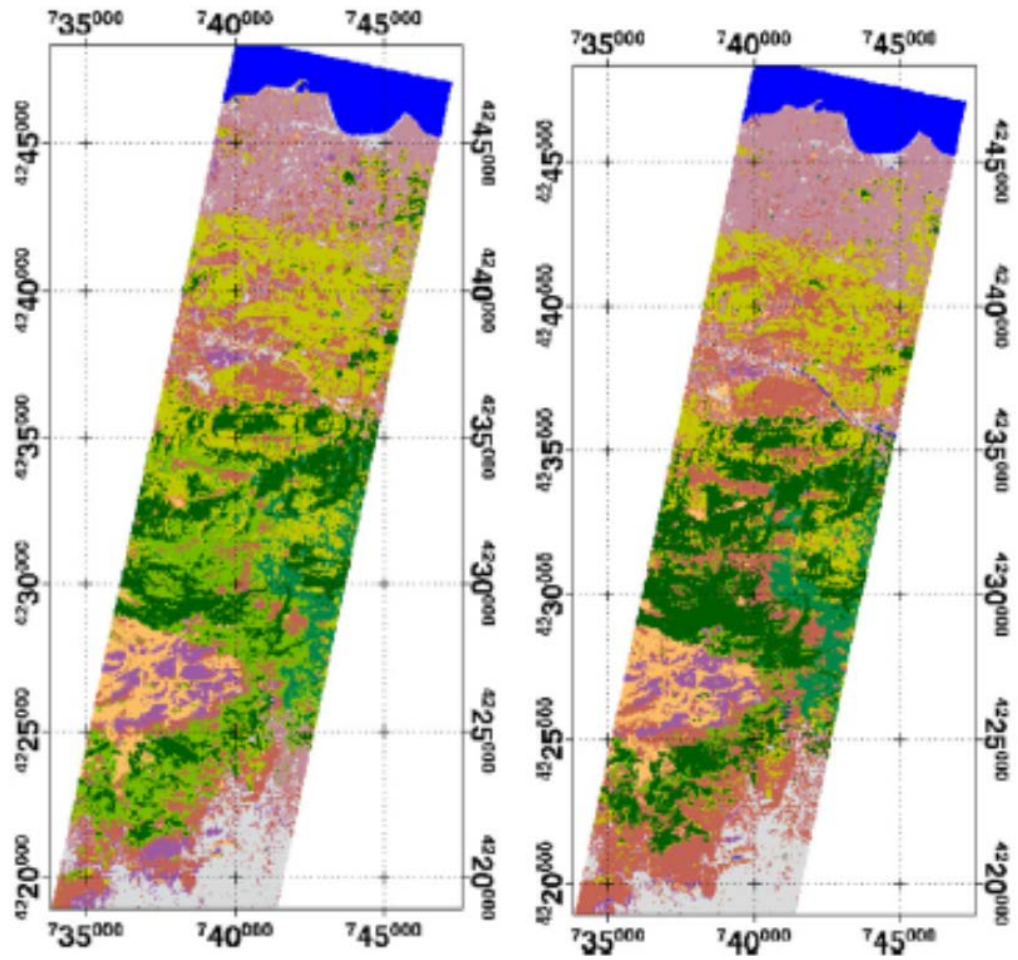

Unclassified

SEA

CONIFER FORESTS

BAOADLEAVED FOAESTS

SCHEROPHYLOUS VEGETATION TRANSITIONAL WOODLAND SCRUBLAND SPARSELY VEGETATED AREAS HETEROGENEOUS AGRICULTURAL AREAS URBAN AREAS

BURNT AREAS

BARE ROCKS

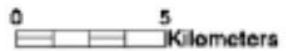

Figure 3. The Hyperion pixel-based classification using the SVMs RBF classifier (top image) and the ANNs (bottom image), (Adapted from Petropoulos et al., 2015)

In previous research several techniques such as MLC, SAM, SVM, ANN, decision tree (Dixon and Candade 2008; Srivastava et al., 2012) have been employed on Landsat TM, MSS, MODIS data to assess and evaluate the LULC cover. Based on findings, researchers suggest that both ANN and SVM outperform MLC on ETM+, SVM perform well with TM data (Dixon and Candade 2008) while ANN 
perform well against SVM, MLC with TM/ETM+ (Huang $C$ et al. 2002). Table 4 provides a summary of examples where different classifiers incorporated by several researchers for LULC mapping. Amarsaikhan et al. (2010) employed wavelet-based fusion, Brovey transforms, Elhers fusion and principal component analysis for multi-source and multi-temporal data and concluded that the classification accuracy was better with the integrated images as compared to the individual data. Klein et al. (2012) used time-series MODIS derived seasonal metrics for regional LULC change analysis using decision tree classifier based on a C5 algorithm and demonstrated the usefulness of decision tree for classification ability due to the incorporation of seasonal metrics.

532 Recently, Clark and Kilham (2016) explored the RF algorithm utilising three independent variables, (reflectance, MNF, matrices and temporal-seasonal variables), for simulated HyspIRI image classification for land cover. They employed RF and multi-temporal matrices to achieve the international Land Cover Classification System (LCCS) in two level of classification for simulated HyspIRI images, concluding RF as superior to others for regional and global scales used in the study. Following this, Guidici and Clark (2017) demonstrated the implementation and robustness of ANN (overall classification accuracy 89.9\%) and SVM (overall classification accuracy 89.5\%) over RF with improved land cover mapping results. The above case studies illustrated appropriate classifier algorithm utilised with the types of datasets have different perspective results depending on the user needs. Authors gave insight to the classification algorithm implementation for achieving improved accuracy results for datasets utilised in the study, thus resulting in distinctive target feature identification, an an interpretation with in spatial-spectral-temporal domain for assessment of land cover.

Table 4 Different classification techniques used for classification of LULC and its changes

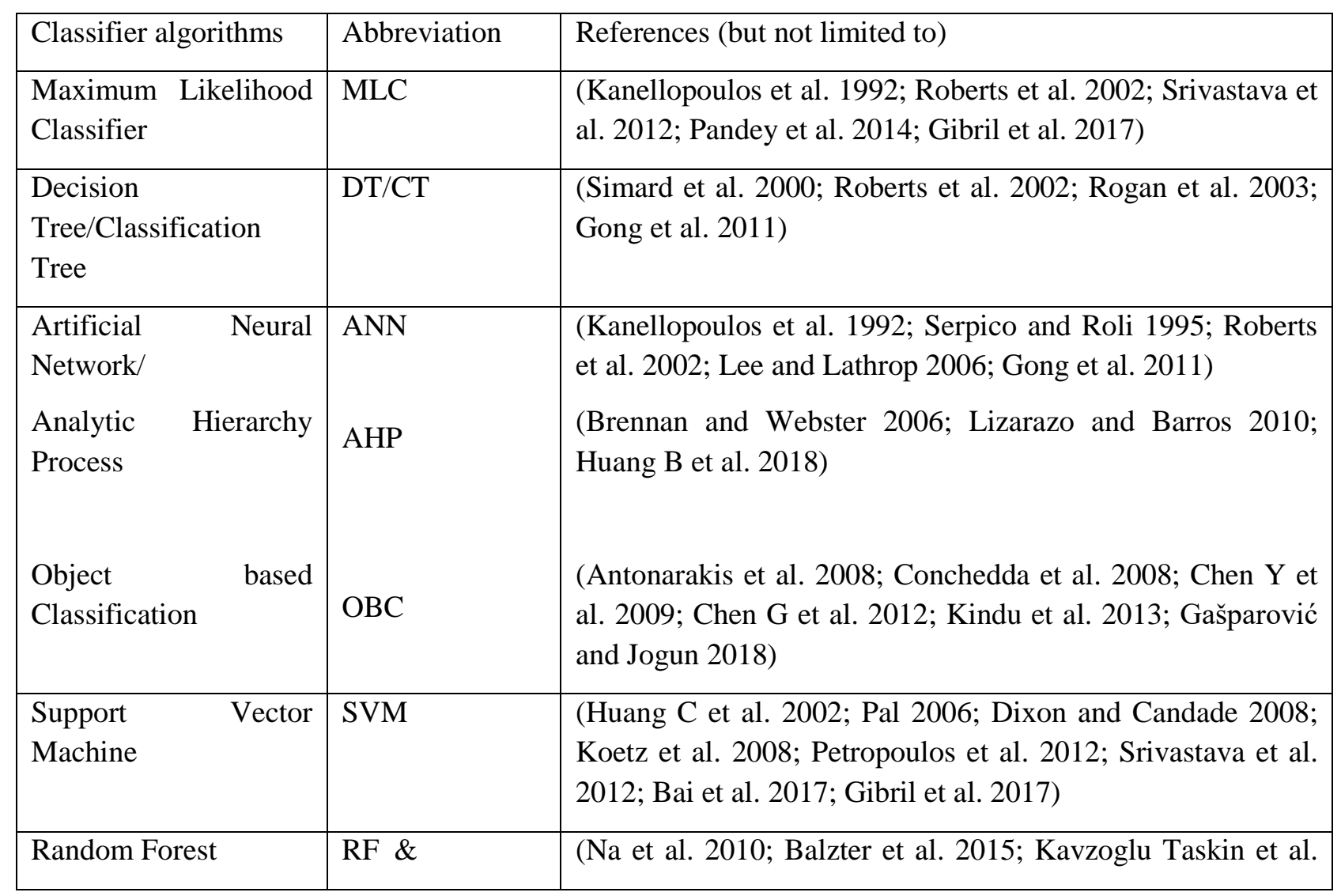




\begin{tabular}{|lr|l|l|}
\hline $\begin{array}{l}\text { \& } \\
\text { Markov Random Field }\end{array}$ & MRF & 2015) \\
& (Solberg et al. 1996; Zhu et al. 2012; Hamad et al. 2018) \\
\hline $\begin{array}{l}\text { Spectral } \\
\text { Mapper }\end{array}$ & Angle & SAM & (Pandey et al. 2014; Gibril et al. 2017; Krishna et al. 2018) \\
\hline $\begin{array}{l}\text { Iterative } \\
\begin{array}{l}\text { Organizing } \\
\text { Analysis }\end{array}\end{array}$ & $\begin{array}{l}\text { Self- } \\
\text { Data }\end{array}$ & $\begin{array}{l}\text { ISODATA } \\
\text { Kmeans }\end{array}$ & $\begin{array}{l}\text { (Engdahl and Hyyppa 2003; Herold et al. 2005; Thenkabail } \\
\text { et al. 2005; Chavula et al. 2011; Kassawmar et al. 2018) } \\
\text { (Werner et al. 2014; Kavzoglu T and Tonbul 2018) }\end{array}$ \\
\hline
\end{tabular}

548 Traditional classification methods in complex urban regions using hard segmentation approaches result in low accuracy and furthermore they do not generate a meaningful crisp thematic image for analysis (Lizarazo and Barros 2010). Therefore, the use of advanced fuzzy approach helps to generate meaningful crisp image objects using segmentation techniques (Kindu et al. 2013). The problem of hard segmentation was ruled out during fuzzy methods, while Markov model can predict better and easier future changes. The use of multi-temporal than single-date classification approaches for LULC mapping increases accuracy with improved tools and techniques (MacLean and Congalton 2013). Multiple Landsat images have been used within the time-period 1986-2010 using object-based image analysis approaches in combination with Classification And Regression Tree (CART). Two images for each year were generated using the above two techniques to perform the changes analysis and reported the enhanced accuracy. Also, Budreski et al. (2007) used paired techniques, CART, and $\mathrm{kNN}$, on multi-temporal datasets of Landsat TM/ETM+ images resulting in an improved accuracy ranging from $77 \%$ to $91 \%$. Other techniques such as Principal Component Analysis (PCA), Spectral Mixture Analysis (SMA), Minimum Noise Fraction transformation (MNF), Linear Spectral Unmixing (LSU) Matched filtering techniques (Braswell et al., 2003), have been also applied to reduce the data dimensionality especially of big datasets (either space-borne or air-borne hyperspectral images) for LULC mapping. Some studies demonstrated the use of standardized and unstandardized PC bands with Landsat TM imageries for LULC classification (Batistella 1999, 2000; Alexandris, Gupta, et al. 2017; Alexandris, Koutsias, et al. 2017).

\section{LULC changes dynamics- An approach towards temporal dimension}

To successfully manage the Earth's natural resources, it is important to provide accurate maps of LULC and its changes (Campbell et al. 2015). Changes in the properties and attribute of the spatial feature cause changes in land cover from one unit to another. LULC changes are resulting from conversion or modification from one class to another (complete change in the spatial units from one class to other class such as deforestation, or change in the urban expansion, which is irreversible). The amount and magnitude of LULC changes, their dynamics and patterns may differ with different factors, such as landscape location (Rindfuss et al. 2004), slope and elevation (Nelson and Geoghegan 2002; Tegene 2002; Poyatos et al. 2003), time period being considered for the study (Weng 2002). These factors can lead to heterogeneity in the direction, pattern, type, and magnitude of changes and depend upon the need of the region and available resources. The typical examples of LULC changes involve conversion (urban built up and urban sprawl, deforestation) and modification (fallow land to 580 agricultural land, water logging, flooding) which can be studied and identified by the change detection 
There is evidence that population moves to occupy the vacant, fallow, and agricultural, or destroy forestland for their own requirements such as food, shelters, and economic development. Sometimes it leads to conversion of agricultural land to urban settlements, forest to deforested regions, or gradual transformation of rural area to urban area (Stamou et al. 2016; Xystrakis et al. 2017). The migration of population to a new area leads to urban sprawl resulting in a change in the land use pattern. For future trend in response to moving urban outskirts, Markov model can predict quantitatively the trends of future LULC of that region as move take place due to increasing demand of land consumption in parallel to the exponential growth of population (Sharma et al 2012). The built-up environment configuration influences the management processes for development and other municipality works. Four aspects of change detection that are important when monitoring natural resources are (i) detecting the changes have been occurred, (ii) identifying the nature of the changes, (iii) measuring the areal extent of the changes, and (iv) assessing the spatial pattern of the changes (MacLean and Congalton 2013).

Various methods are available for assessing the change dynamics such as image differencing, image rationing, Change Vector Analysis (CVA), and image regression to assess their effectiveness for detecting land use/cover change, but no single approach can solve the problem of land use change detection (Civco et al. 2002; Berberoglu and Akin 2009). As different change detection algorithms have their own merits and advantages and demerits over other approach and no single approach is optimal and applicable to all study cases. However, the selection of an appropriate change detection technique is important for accurate outcome and enhanced change dynamic mapping (Berberoglu and Akin 2009; Sharma et al. 2012). Different studies show that image differencing (Sharma et al. 2012; Leichtle et al. 2017; Zaidi et al. 2017), principal component analysis (Koutsias et al. 2009), and postclassification comparison (Lark et al. 2017; Wu et al. 2017) are the most common methods used for change detection (Gu et al. 2017). In practice, different techniques are often compared to find the most useful change detection results for a specific application ( $\mathrm{Lu}$ et al. 2002). There are several review studies on change detection techniques and algorithms using different datasets. (See Zhu (2017) for a comprehensive review on change detection and algorithms using Landsat time series data and Lu et al. (2004) and Jianya et al. (2008) for comparative study on change detection methods)

Recently, concluded in their study that utilisation of additional features is needed such as spectral indices, spectral transformation, textural and topographic features along with spectral features from Landsat datasets to improve the overall accuracy and avoid the misclassification between different classes. Demonstration of LULC change dynamics were linked to human activities as well as to temperature and precipitation which marked a significant contribution towards conversion from one class to another (Bai et al. 2017). Also, spectral indices in combination with spectral features were used by Pandey et al. (2013) to demonstrate the change dynamics of sandy regions and conversion of agricultural lands into sandy degraded regions using temporal Landsat dataset in the Jhunjhunu region India.

620 Bai et al. (2017) used multi-temporal Landsat data (1976, 1984, 1995, 2006, and 2014) to quantify the intensive LULC exploring the change patterns and identification of wetland trajectories for the time period 1976-2014. Feng et al. (2015) demonstrated that temporal datasets can be used to illustrate the regional coverage in terms of within the city and outside the city for grassland, urban population, and fallow land. The spatial-temporal analysis by Feng et al. (2015) indicated an increase in the cropland area to about 8.65\% per year over the Yellow River Delta region using multi-temporal datasets (1986, 1995, 2005 and 2015) through random forest classifier. Further, Zhang et al. (2017) demonstrated the use of temporal data for transition studies and suggested an improvement in the landscape due to 
human activities. Similarly, Zhang et al. (2017) demonstrated the wetland change trajectory such as degradation or artificialization (Cohen et al. 2010; Kennedy et al. 2010) and LULC dynamics based on enhanced transition matrix for the period 1976-2014 nearby Yellow River Delta regions using temporal Landsat datasets (1976, 1984, 1995, 2004, and 2014).

632 There are some examples of studies revealing the robustness of temporal SAR data for LULC 633 mapping and change analysis. For instance, Zhu et al. (2012) experimented with multi-season Landsat 634 ETM+ and Advanced Land Observing Satellite (ALOS) Phased Array Type L-band Synthetic Aperture Radar (PALSAR) SAR data. The highest map accuracy was achieved with Landsat and PALSAR data used together where the lowest accuracy was generated with textural variables from PALSAR data. Individual PALSAR images resulted to an accuracy of 31\%, Landsat of $78 \%$, multiseasonal Landsat of $87 \%$, Landsat derived textural feature of $92.69 \%$, while Landsat and PALSAR together have surprisingly highest result of about $93.82 \%$, demonstrating therefore the importance of multi-seasonal, multi-source, multi-sensor in combination with other variables, which can definitely

\section{Conclusions}

644 As it is clearly evidenced from our review, EO provides an informative source of data covering entire globe in a spatial and spectral resolution appropriate to better and easier classify land cover than traditional or conventional methods. The use of high spatial and spectral resolution imagery from EO sensors has increased remarkably over the past decides, as more and more platforms are placed in orbit and new applications emerge in different disciplines. As the spatial dimension increases, the mapping accuracy increases irrespective of the other dimensions, whereas, the increase in spectral resolution lead to data dimensionality, and other factors also play an important role such as the classification techniques. While the spectral resolution leads to the differentiation of features types, it also adds to data dimensionality making huge voluminous data. Therefore, the probability of increasing accuracy results depends upon the spectral resolution as well as other factors such as spatial resolution simultaneously. For example, for the selection of the most appropriate satellite sensor either multispectral or hyperspectral in LULC mapping, the properties of the area under investigation (e.g. land cover fragmentation, parcels size, cultivation procedures) should also be considered. For example, in certain occasions where Sentinel2 might be a better choice than Landsat and vice-versa or Hyperspectral data might be better choice in case of agricultural parcels as compared to homogenous land parcels.

The temporal resolution plays an important role in detection of changes and their dynamics with time period, frequent temporal resolution such as seasonal temporal dimensions are required to monitor the crop types, growth, and production, annual temporal analysis is required for the urban, forest cover etc. the increased temporal resolution provides the detailed study about the features in concern. All the three input dimensions (spatial, spectral and temporal) have an impact on the mapping accuracy, either individually or altogether, an increase in one of the dimension increases the mapping accuracy. To achieve high classification accuracy each dimension plays an important role, and contributes significantly to the output. From spatial to spectral, spectral to temporal dimension, are required to assess the mapping and change dynamics consistently and accurately.

Because of the varying nature of the landscape and several types of sensors, classification techniques also play an important role in the mapping accuracy, parametric or non-parametric, for multispectral to hyperspectral data. Indeed, over the recent years, a number of classifier algorithms have been utilised and employed in LULC mapping such as supervised or unsupervised, soft or hard classifiers, 
673 parametric or non-parametric. Considering the necessity of implementing appropriate classifiers for 674 LULC mapping, several other factors must be studied to overcome pixel size and mixed features 675 issues to outperform one technique over other. Therefore, one should know about the input 676 dimensions, types of remotely sensed data and appropriate classifiers implementation in the LULC mapping for their advantages and drawbacks using a different combination of the all approaches used 678 in the study.

\section{Acknowledgements}

Authors are thankful to Shiv Nadar University for providing the help and facilities. Authors are also thankful to Remote Sensing Laboratory (RSL) colleagues for cooperation and RSL, Tel Aviv University for help and support during idea development. Authors are thankful to RSL colleagues for cooperation. Dr Petropoulos's contribution to this work has been supported by the EU Marie Curie Project- ENViSIon-EO (project contract-ID 752094). We are thankful to anonymous reviewers for their constructive and thoughtful inputs in the manuscript. Authors declare no conflict of interests.

\section{References}

Adar S, Shkolnisky Y, Ben Dor E. 2014. A new approach for thresholding spectral change detection using multispectral and hyperspectral image data, a case study over Sokolov, Czech republic. International journal of remote sensing. 35(4):1563-1584.DOI: https://doi.org/10.1080/01431161.2013.878062.

Alexandris N, Gupta S, Koutsias N. 2017. Remote sensing of burned areas via PCA, Part 1; centering, scaling and EVD vs SVD. Open Geospatial Data, Software and Standards. 2(1):17.DOI: 10.1186/s40965-017-00281.

Alexandris N, Koutsias N, Gupta S. 2017. Remote sensing of burned areas via PCA, Part 2: SVD-based PCA using MODIS and Landsat data. Open Geospatial Data, Software and Standards. 2(1):21.DOI: 10.1186/s40965-017-0029-0.

Amarsaikhan D, Blotevogel H, Van Genderen J, Ganzorig M, Gantuya R, Nergui B. 2010. Fusing high-resolution SAR and optical imagery for improved urban land cover study and classification. International Journal of Image and Data Fusion. 1(1):83-97.

Amarsaikhan D, Ganzorig M, Ache P, Blotevogel H. 2007. The integrated use of optical and InSAR data for urban land-cover mapping. International Journal of Remote Sensing. 28(6):1161-1171.

Anderson JR. 1976. A land use and land cover classification system for use with remote sensor data. Vol. 964. US Government Printing Office. (Geological Survey Professional Paper 964.

Antonarakis A, Richards KS, Brasington J. 2008. Object-based land cover classification using airborne LiDAR. Remote Sensing of Environment. 112(6):2988-2998.

Arino O, Bicheron P, Achard F, Latham J, Witt R, Weber J-L. 2008. GlobCover: The most detailed portrait of Earth. Eur Space Agency. 136:25-31.

Bai X, Sharma RC, Tateishi R, Kondoh A, Wuliangha B, Tana G. 2017. A Detailed and High-Resolution Land Use and Land Cover Change Analysis over the Past 16 Years in the Horqin Sandy Land, Inner Mongolia. Hindawi Mathematical Problems in Engineering. 2017(dArticle ID 1316505, 13 pages).DOI: 10.1155/2017/1316505.

Bajocco S, De Angelis A, Perini L, Ferrara A, Salvati L. 2012. The impact of land use/land cover changes on land degradation dynamics: a Mediterranean case study. Environmental management. 49(5):980-989.DOI: 10.1007/s00267-012-9831-8.

Balzter H, Cole B, Thiel C, Schmullius C. 2015. Mapping CORINE land cover from Sentinel-1A SAR and SRTM digital elevation model data using random forests. Remote Sensing. 7(11):14876-14898.DOI: $10.3390 /$ rs71114876. 
Bartels M, Wei H. 2006. Rule-based improvement of maximum likelihood classified LIDAR data fused with coregistered bands, Annual Conference of the Remote Sensing and Photogrammetry Society, CD Proceedings, 05-08 September 2006 (pp. 1-9).

Bartholomé E, Belward AS. 2005. GLC2000: a new approach to global land cover mapping from Earth observation data. International Journal of Remote Sensing. 26(9):1959-1977.DOI: 10.1080/01431160412331291297.

Batistella M. 1999. Exploratory comparison between maximum likelihood and spatial-spectral classifiers using Landsat TM bands and principal component analysis for selected areas in Tomé Açú Brazilian Amazon. Located at: In: CONGRESSO E FEIRA PARA USUÁRIOS DE GEOPROCESSAMENTO DA AMÉRICA LATINA (GIS BRASIL' 99), 5., 1999, Salvador. Anais $9 \mathrm{p}$.

Batistella M. 2000. Extracting earth surface feature information for land-use/land cover classifications in Amazonia: the role of remote sensors. Located at: In: GISBRASIL 2000: SHOW DE GEOTECNOLOGIAS, 6., 2000, Salvador. Anais: A era.

BELSPO. 2013. Sensors. Belgium: Belgian Earth Observation Platform; [accessed 201621 December]. http://eo.belspo.be/Directory/SensorDetail.aspx?senID=69.

Ben-Dor E. 2002. Quantitative remote sensing of soil properties. Advances in Agronomy. 75:173-243.DOI: https://doi.org/10.1016/S0065-2113(02)75005-0.

Ben-Dor E, Banin A. 1995. Near infrared analysis (NIRA) as a method to simultaneously evaluate spectral featureless constituents in soils. Soil Science. 159(4):259-270.

Ben-Dor E, Irons J, Epema G. 1999. Soil reflectante. Manual of Remote Sensing: Remote Sensing for Earth Science; Rencz, AN, Ryerson, RA, Eds.111-187.

Berberoglu S, Akin A. 2009. Assessing different remote sensing techniques to detect land use/cover changes in the eastern Mediterranean. International Journal of Applied Earth Observation and Geoinformation. 11(1):46-53.DOI: https://doi.org/10.1016/j.jag.2008.06.002.

Blaschke T. 2010. Object based image analysis for remote sensing. ISPRS Journal of Photogrammetry and Remote Sensing. 65(1):2-16.DOI: https://doi.org/10.1016/j.isprsjprs.2009.06.004.

Bora M, Goswami DC. 2016. Spatio-temporal landuse/landcover (LULC) change analysis of Kolong River basin, Assam, India using geospatial technologies. Int J Geomat Geosci. 6(3):1676-1684.

Borak J, Lambin E, Strahler A. 2000. The use of temporal metrics for land cover change detection at coarse spatial scales. International Journal of Remote Sensing. 21(6-7):1415-1432.DOI: 10.1080/014311600210245.

Brennan R, Webster T. 2006. Object-oriented land cover classification of lidar-derived surfaces. Canadian Journal of Remote Sensing. 32(2):162-172.DOI: https://doi.org/10.5589/m06-015.

Brown AR, Petropoulos GP, Ferentinos KP. 2018. Appraisal of the Sentinel-1 \& 2 use in a large-scale wildfire assessment: A case study from Portugal's fires of 2017. Applied geography. 100:78-89.DOI: 10.1016/j.apgeog.2018.10.004.

Buckley JR, Smith AM. 2010. Monitoring grasslands with RADARSAT 2 quad-pol imagery. 2010 IEEE International Geoscience and Remote Sensing Symposium; 2010: IEEE.

Budreski KA, Wynne RH, Browder JO, Campbell JB. 2007. Comparison of segment and pixel-based nonparametric land cover classification in the Brazilian Amazon using multitemporal Landsat TM/ETM+ imagery. Photogrammetric Engineering \& Remote Sensing. 73(7):813-827.DOI: https://doi.org/10.14358/PERS.73.7.813.

Campbell M, Congalton RG, Hartter J, Ducey M. 2015. Optimal land cover mapping and change analysis in northeastern oregon using Landsat imagery. Photogrammetric Engineering \& Remote Sensing. 81(1):37-47.DOI: https://doi.org/10.14358/PERS.81.1.37.

Camps-Valls G, Bruzzone L. 2005. Kernel-based methods for hyperspectral image classification. IEEE Transactions on Geoscience and Remote Sensing. 43(6):1351-1362.DOI: 10.1109/TGRS.2005.846154.

Cass A, Petropoulos GP, Ferentinos KP, Pavlides A, Srivastava PK. 2019. Exploring the synergy between Landsat and ASAR towards improving thematic mapping accuracy of optical EO data. Applied Geomatics.112.DOI: 10.1007/s12518-019-00258-7 [in press].

Charaniya AP, Manduchi R, Lodha SK. 2004. Supervised parametric classification of aerial lidar data. Conference on Computer Vision and Pattern Recognition Workshop; 2004; pp. 30-30.: IEEE.

Chatziantoniou A, Psomiadis E, Petropoulos G. 2017. Co-Orbital Sentinel 1 and 2 for LULC mapping with emphasis on wetlands in a mediterranean setting based on machine learning. Remote Sensing. 9(12):1259. 
Chavula G, Brezonik P, Bauer M. 2011. Land use and land cover change (LULC) in the Lake Malawi Drainage Basin, 1982-2005. International Journal of Geosciences. 2(02):172.DOI: 10.4236/ijg.2011.22018.

Chen B, Huang B, Xu B. 2017. Multi-source remotely sensed data fusion for improving land cover classification. ISPRS Journal of Photogrammetry and Remote Sensing. 124:27-39.

Chen G, Hay GJ, Carvalho LM, Wulder MA. 2012. Object-based change detection. International Journal of Remote Sensing. 33(14):4434-4457.DOI: https://doi.org/10.1080/01431161.2011.648285.

Chen Y, Su W, Li J, Sun Z. 2009. Hierarchical object oriented classification using very high resolution imagery and LIDAR data over urban areas. Advances in Space Research. 43(7):1101-1110.DOI: https://doi.org/10.1016/j.asr.2008.11.008.

Civco DL, Hurd JD, Wilson EH, Song M, Zhang Z. 2002. A comparison of land use and land cover change detection methods. ASPRS-ACSM Annual Conference.

Clark ML, Kilham NE. 2016. Mapping of land cover in northern California with simulated hyperspectral satellite imagery. ISPRS Journal of Photogrammetry and Remote Sensing. 119:228-245.DOI: https://doi.org/10.1016/j.isprsjprs.2016.06.007.

Clerici N, Valbuena Calderón CA, Posada JM. 2017. Fusion of Sentinel-1A and Sentinel-2A data for land cover mapping: a case study in the lower Magdalena region, Colombia. Journal of Maps. 13(2):718-726.DOI: https://doi.org/10.1080/17445647.2017.1372316.

Cohen WB, Yang Z, Kennedy R. 2010. Detecting trends in forest disturbance and recovery using yearly Landsat time series: 2 . TimeSync-Tools for calibration and validation. Remote Sensing of Environment. 114(12):2911-2924.

Cole B, Smith G, Balzter H. 2018. Acceleration and fragmentation of CORINE land cover changes in the United Kingdom from 2006-2012 detected by Copernicus IMAGE2012 satellite data. International Journal of Applied Earth Observation and Geoinformation. 73:107-122.DOI: https://doi.org/10.1016/j.jag.2018.06.003.

Colson D, Petropoulos GP, Ferentinos KP. 2018. Exploring the potential of Sentinels-1 \& 2 of the Copernicus Mission in support of rapid and cost-effective wildfire assessment. International journal of applied earth observation and geoinformation. 73:262-276.DOI: doi.org/10.1016/j.jag.2018.06.011.

Conchedda G, Durieux L, Mayaux P. 2008. An object-based method for mapping and change analysis in mangrove ecosystems. ISPRS Journal of Photogrammetry and Remote Sensing. 63(5):578-589.DOI: https://doi.org/10.1016/j.isprsjprs.2008.04.002.

Cook BD, Bolstad PV, Næsset E, Anderson RS, Garrigues S, Morisette JT, Nickeson J, Davis KJ. 2009. Using LiDAR and quickbird data to model plant production and quantify uncertainties associated with wetland detection and land cover generalizations. Remote Sensing of Environment. 113(11):2366-2379.DOI: https://doi.org/10.1016/j.rse.2009.06.017.

da Costa Freitas C, de Souza Soler L, Sant'Anna SJS, Dutra LV, Dos Santos JR, Mura JC, Correia AH. 2008. Land use and land cover mapping in the Brazilian Amazon using polarimetric airborne P-band SAR data. IEEE Transactions on Geoscience and Remote Sensing. 46(10):2956-2970.DOI: 10.1109/TGRS.2008.2000630.

Deng L, Yan Y-n, Sun C. 2015. Use of sub-aperture decomposition for supervised PolSAR classification in urban area. Remote Sensing. 7(2):1380-1396.DOI: https://doi.org/10.3390/rs70201380.

Dezso Z, Bartholy J, Pongracz R, Barcza Z. 2005. Analysis of land-use/land-cover change in the Carpathian region based on remote sensing techniques. Physics and Chemistry of the Earth, Parts $A / B / C$. 30(1):109-115.DOI: https://doi.org/10.1016/j.pce.2004.08.017.

Di Gregorio A. 2005. Land cover classification system: classification concepts and user manual: LCCS. Food \& Agriculture Org. 8).

Dixon B, Candade N. 2008. Multispectral landuse classification using neural networks and support vector machines: one or the other, or both? International Journal of Remote Sensing. 29(4):1185-1206.DOI: https://doi.org/10.1080/01431160701294661.

Dong J, Zhuang D, Huang Y, Fu J. 2009. Advances in multi-sensor data fusion: Algorithms and applications. Sensors. 9(10):7771-7784.DOI: 10.3390/s91007771.

Elatawneh A. 2015. Investigations into the potentials of hyperspectral and multi-seasonal/multispectral satellites data for forest parameter determination. Technische Universität München.

Engdahl ME, Hyyppa JM. 2003. Land-cover classification using multitemporal ERS-1/2 InSAR data. IEEE Transactions on Geoscience and Remote Sensing. 41(7):1620-1628.DOI: 10.1109/TGRS.2003.813271. 
Erdogan N, Nurlu E, Guvensen A, Erdem U. 2015. LAND USE/LAND COVER CHANGE DETECTION FOR ENVIRONMENTAL MONITORING IN TURKEY. A CASE STUDY IN KARABURUN PENINSULA. JOURNAL OF ENVIRONMENTAL PROTECTION AND ECOLOGY. 16(1):252-263.

ESA. 2017. CORINE land cover. accessed May 12, 2017. ; [accessed]. https://www.eea.europa.eu/publications/CORO-landcover

ESA. 2018. Missions. Europe: European Space Agency; [accessed $2018 \quad 10$ Jan]. https://earth.esa.int/web/guest/missions.

Evans TL, Costa M, Telmer K, Silva TS. 2010. Using ALOS/PALSAR and RADARSAT-2 to map land cover and seasonal inundation in the Brazilian Pantanal. IEEE Journal of Selected Topics in Applied Earth Observations and Remote Sensing. 3(4):560-575.DOI: 10.1109/JSTARS.2010.2089042.

Fauvel M, Benediktsson JA, Chanussot J, Sveinsson JR. 2008. Spectral and spatial classification of hyperspectral data using SVMs and morphological profiles. IEEE Transactions on Geoscience and Remote Sensing. 46(11):3804-3814.DOI: 10.1109/IGARSS.2007.4423943.

Fauvel M, Chanussot J, Benediktsson JA. 2012. A spatial-spectral kernel-based approach for the classification of remote-sensing images. Pattern Recognition. 45(1):381-392.DOI: https://doi.org/10.1016/j.patcog.2011.03.035.

Feng Q, Gong J, Liu J, Li Y. 2015. Monitoring Cropland Dynamics of the Yellow River Delta based on MultiTemporal Landsat Imagery over 1986 to 2015. Sustainability. 7(11):14834-14858.DOI: https://doi.org/10.3390/su71114834.

Fisher P, Comber AJ, Wadsworth R. 2005. Land use and land cover: contradiction or complement. In Representing GIS. edited by Peter Fisher, David Unwin:85-98, Wiley, Chichester.

Friedl MA, Mclver DK, Hodges JC, Zhang X, Muchoney D, Strahler AH, Woodcock CE, Gopal S, Schneider A, Cooper A. 2002. Global land cover mapping from MODIS: algorithms and early results. Remote Sensing of Environment. 83(1):287-302.DOI: https://doi.org/10.1016/S0034-4257(02)00078-0.

Friedl MA, Sulla-Menashe D, Tan B, Schneider A, Ramankutty N, Sibley A, Huang X. 2010. MODIS Collection 5 global land cover: Algorithm refinements and characterization of new datasets. Remote sensing of Environment. 114(1):168-182.DOI: https://doi.org/10.1016/j.rse.2009.08.016.

Gašparović M, Jogun T. 2018. The effect of fusing Sentinel-2 bands on land-cover classification. International journal of remote sensing. 39(3):822-841.DOI: https://doi.org/10.1080/01431161.2017.1392640.

Gessner U, Klein D, Conrad C, Schmidt M, Dech S. 2009. Towards an automated estimation of vegetation cover fractions on multiple scales: Examples of Eastern and Southern Africa. Proceedings of the 33rd International Symposium of Remote Sensing of the Environment, Stresa, Italy; 2009.

Gibril MBA, Bakar SA, Yao K, Idrees MO, Pradhan B. 2017. Fusion of RADARSAT-2 and multispectral optical remote sensing data for LULC extraction in a tropical agricultural area. Geocarto international. 32(7):735-748.DOI: 10.1080/10106049.2016.1170893.

Gidey E, Dikinya O, Sebego R, Segosebe E, Zenebe A. 2017. Modeling the Spatio-temporal dynamics and evolution of land use and land cover (1984-2015) using remote sensing and GIS in Raya, Northern Ethiopia. Modeling Earth Systems and Environment. 3(4):1285-1301.DOI: https://doi.org/10.1007/s40808-017-0375-z.

Gillespie TW, Foody GM, Rocchini D, Giorgi AP, Saatchi S. 2008. Measuring and modelling biodiversity from space. Progress in Physical Geography. 32(2):203-221.

Gong B, Im J, Mountrakis G. 2011. An artificial immune network approach to multi-sensor land use/land cover classification. Remote Sensing of Environment. 115(2):600-614.DOI: https://doi.org/10.1016/j.rse.2010.10.005.

Gould W. 2000. Remote sensing of vegetation, plant species richness, and regional biodiversity hotspots. Ecological applications. 10(6):1861-1870.

Grecchi RC, Gwyn QHJ, Bénié GB, Formaggio AR, Fahl FC. 2014. Land use and land cover changes in the Brazilian Cerrado: A multidisciplinary approach to assess the impacts of agricultural expansion. Applied Geography. 55:300-312.DOI: https://doi.org/10.1080/1747423X.2016.1182221.

Gu W, Lv Z, Hao M. 2017. Change detection method for remote sensing images based on an improved Markov random field. Multimedia Tools and Applications. 76(17):17719-17734.DOI: 10.1007/s11042-0152960-3.

Guidici D, Clark ML. 2017. One-Dimensional convolutional neural network land-cover classification of multiseasonal hyperspectral imagery in the San Francisco Bay Area, California. Remote Sensing. 9(6):629.DOI: https://doi.org/10.3390/rs9060629. 
Haack BN, Herold ND, Bechdol MA. 2000. Radar and optical data integration for land-use/land-cover mapping. Photogrammetric Engineering and Remote Sensing. 66(6):709-716.

Hagensieker R, Roscher R, Rosentreter J, Jakimow B, Waske B. 2017. Tropical land use land cover mapping in Pará (Brazil) using discriminative Markov random fields and multi-temporal TerraSAR-X data. International journal of applied earth observation and geoinformation. 63:244-256.DOI: 10.1016/j.jag.2017.07.019.

Hall DL, McMullen SA. 2004. Mathematical techniques in multisensor data fusion. Artech House.

Hamad R, Balzte H, Kolo K. 2018. Predicting Land Use/Land Cover Changes Using a CA-Markov Model under Two Different Scenarios. Sustainability MDPI. 10(3421):1-23.DOI: 10, 3421; doi:10.3390/su10103421

Hansen MC, Loveland TR. 2012. A review of large area monitoring of land cover change using Landsat data. Remote sensing of Environment. 122:66-74.DOI: https://doi.org/10.1016/j.rse.2011.08.024.

Hegde G, Ahamed JM, Hebbar R, Raj U. 2014. Urban land cover classification using hyperspectral data. The International Archives of the Photogrammetry, Remote Sensing and Spatial Information Sciences Volume XL-8, 2014 ISPRS Technical Commission VIII Symposium, 09 - 12 December 2014, Hyderabad, India.

Heiden U, Segl K, Roessner S, Kaufmann H. 2007. Determination of robust spectral features for identification of urban surface materials in hyperspectral remote sensing data. Remote Sensing of Environment. 111(4):537-552.DOI: https://doi.org/10.1016/j.rse.2007.04.008.

Henderson F. 1975. Radar for small-scale land-use mapping. Photogrammetric Eng Remote Sensing. 41(3):307319.DOI: 19750051177 (Acquired Dec 01, 1995) Accession Number: 75A35249.

Henderson FM, Xia Z-G. 1997. SAR applications in human settlement detection, population estimation and urban land use pattern analysis: a status report. IEEE transactions on geoscience and remote sensing. 35(1):79-85.DOI: 10.1109/36.551936.

Herold M, Couclelis H, Clarke KC. 2005. The role of spatial metrics in the analysis and modeling of urban land use change. Computers, Environment and Urban Systems. 29(4):369-399.DOI: https://doi.org/10.1016/j.compenvurbsys.2003.12.001.

Huang B, Zhao B, Song Y. 2018. Urban land-use mapping using a deep convolutional neural network with high spatial resolution multispectral remote sensing imagery. Remote Sensing of Environment. 214:7386.DOI: https://doi.org/10.1016/j.rse.2018.04.050.

Huang C, Davis L, Townshend J. 2002. An assessment of support vector machines for land cover classification. International Journal of remote sensing. 23(4):725-749.DOI: https://doi.org/10.1080/01431160110040323.

Huang $X$, Zhang L. 2011. A multidirectional and multiscale morphological index for automatic building extraction from multispectral GeoEye-1 imagery. Photogrammetric Engineering \& Remote Sensing. 77(7):721-732.DOI: 10.14358/PERS.77.7.721.

Jianya G, Haigang S, Guorui M, Qiming Z. 2008. A review of multi-temporal remote sensing data change detection algorithms. The International Archives of the Photogrammetry, Remote Sensing and Spatial Information Sciences. 37(B7):757-762.

Johnson BD, Singh J. 2003. Building the national geobase for Canada. Photogrammetric Engineering \& Remote Sensing. 69(10):1169-1173.DOI: https://doi.org/10.14358/PERS.69.10.1169.

Kabisch N, Selsam P, Kirsten T, Lausch A, Bumberger J. 2019. A multi-sensor and multi-temporal remote sensing approach to detect land cover change dynamics in heterogeneous urban landscapes. Ecological Indicators. 99:273-282.DOI: https://doi.org/10.1016/j.ecolind.2018.12.033.

Kalacska M, Sanchez-Azofeifa GA, Rivard B, Caelli T, White HP, Calvo-Alvarado JC. 2007. Ecological fingerprinting of ecosystem succession: Estimating secondary tropical dry forest structure and diversity using imaging spectroscopy. Remote Sensing of Environment. 108(1):82-96.

Kanellopoulos I, Varfis A, Wilkinson G, Megier J. 1992. Land-cover discrimination in SPOT HRV imagery using an artificial neural network-a 20-class experiment. International Journal of Remote Sensing. 13(5):917924.

Kaplan G, Avdan U. 2018. Sentinel-1 and Sentinel-2 Data Fusion for Mapping and Monitoring Wetlands. Preprints. 2018070244:DOI: 10.20944/preprints201807.200244.v201801.DOI: 10.20944/preprints201807.200244.v201801.

Karathanassi V, Kolokousis $\mathrm{P}$, loannidou S. 2007. A comparison study on fusion methods using evaluation indicators. International Journal of Remote Sensing. 28(10):2309-2341.DOI: https://doi.org/10.1080/01431160600606890. 
Kassawmar T, Eckert S, Hurni K, Zeleke G, Hurni H. 2018. Reducing landscape heterogeneity for improved land use and land cover (LULC) classification across the large and complex Ethiopian highlands. Geocarto international. 33(1):53-69.DOI: 10.1080/10106049.2016.1222637.

Kavzoglu T, Colkesen I, Yomralioglu T. 2015. Object-based classification with rotation forest ensemble learning algorithm using very-high-resolution WorldView-2 image. Remote Sensing Letters. 6(11):834-843.DOI: 10.1080/2150704X.2015.1084550.

Kavzoglu T, Tonbul H. 2018. An experimental comparison of multi-resolution segmentation, SLIC and K-means clustering for object-based classification of VHR imagery. International journal of remote sensing. 39(18):6020-6036.DOI: 10.1080/01431161.2018.1506592.

Kennedy RE, Yang Z, Cohen WB. 2010. Detecting trends in forest disturbance and recovery using yearly Landsat time series: 1. LandTrendr-Temporal segmentation algorithms. Remote Sensing of Environment. 114(12):2897-2910.

Kim Y, Kim Y. 2014. Improved classification accuracy based on the output-level fusion of high-resolution satellite images and airborne LiDAR data in urban area. IEEE Geoscience and Remote Sensing Letters. 11(3):636-640.DOI: 10.1109/LGRS.2013.2273397.

Kindu M, Schneider T, Teketay D, Knoke T. 2013. Land use/land cover change analysis using object-based classification approach in Munessa-Shashemene landscape of the Ethiopian highlands. Remote Sensing. 5(5):2411-2435.DOI: https://doi.org/10.3390/rs5052411.

Klein I, Gessner U, Kuenzer C. 2012. Regional land cover mapping and change detection in Central Asia using MODIS time-series. Applied Geography. 35(1):219-234.

Koetz B, Morsdorf F, Van der Linden S, Curt T, Allgöwer B. 2008. Multi-source land cover classification for forest fire management based on imaging spectrometry and LiDAR data. Forest Ecology and Management. 256(3):263-271.

Koutsias N. 2010. An autologistic regression model for increasing the accuracy of burned surface mapping using Landsat Thematic Mapper data. International Journal of Remote Sensing. 24(10):21992204.DOI: https://doi.org/10.1080/0143116031000082073.

Koutsias N, Karteris M, Fernandez-Palacios A, Navarro C, Jurado J, Navarro R, Lobo A. 1999. Burned land mapping at local scale. In: Chuvieco E, editor. Remote Sensing of Large Wildfires in the European Mediterranean Basin. Berlin Heidelberg: Springer-Verlag; p. 157-187.

Koutsias N, Mallinis G, Karteris M. 2009. A forward/backward principal component analysis of Landsat-7 ETM+ data to enhance the spectral signal of burnt surfaces. ISPRS Journal of Photogrammetry \& Remote Sensing. 64(1):37-46.DOI: https://doi.org/10.1016/j.isprsjprs.2008.06.004.

Krishna G, Sahoo RN, Pradhan S, Ahmad T, Sahoo PM. 2018. Hyperspectral satellite data analysis for pure pixels extraction and evaluation of advanced classifier algorithms for LULC classification. Earth Science Informatics. 11(2):159-170.DOI: 10.1007/s12145-017-0324-4.

Kumar P, Pandey PC, Kumar V, Singh BK, Tomar V, Rani M. 2015. Efficient recognition of forest species biodiversity by inventory-based geospatial approach using LISS IV sensor. IEEE Sensors Journal. 15(3):1884-1891.

Lamine S, Petropoulos GP, Brewer PA, Bachari N-E-I, Srivastava PK, Manevski K, Kalaitzidis C, Macklin MG. 2019. Heavy Metal Soil Contamination Detection Using Combined Geochemistry and Field Spectroradiometry in the United Kingdom. Sensors. 19(4):762.DOI: 10.3390/s19040762.

Lark TJ, Mueller RM, Johnson DM, Gibbs HK. 2017. Measuring land-use and land-cover change using the US department of agriculture's cropland data layer: Cautions and recommendations. International journal of applied earth observation and geoinformation. 62:224-235.DOI: https://doi.org/10.1016/j.jag.2017.06.007.

Lee S, Lathrop RG. 2006. Subpixel analysis of Landsat ETM/sup+/using self-organizing map (SOM) neural networks for urban land cover characterization. IEEE Transactions on Geoscience and Remote Sensing. 44(6):1642-1654.

Leichtle T, Geiß C, Wurm M, Lakes T, Taubenböck H. 2017. Unsupervised change detection in VHR remote sensing imagery-an object-based clustering approach in a dynamic urban environment. International Journal of Applied Earth Observation and Geoinformation. 54:15-27.DOI: https://doi.org/10.1016/j.jag.2016.08.010.

Lillesand T, Kiefer RW, Chipman J. 2014. Remote sensing and image interpretation. John Wiley \& Sons.

Ling F, Li Z, Chen E, Huang Y, Tian X, Schmullius C, Leiterer R, Reiche J, Santoro M. 2012. Forest and Non-Forest mapping with Envisat ASAR images. Journal of Remote Sensing (China). 16(5):1101-1114. 
Ling F, Li Z, Chen E, Huang Y, Tian X, Schmullius C, Leiterer R, Reiche J, Santoro M. 2013. Forest and Non-Forest Mapping with Envisat ASAR Images. Dragon 2 Final Results and Dragon 3 Kickoff Symposium; 2013.

Liu J, Li J. 2013. Land-use and land-cover analysis with remote sensing images. Information Science and Technology (ICIST), 2013 International Conference on; 2013: IEEE.

Lizarazo I, Barros J. 2010. Fuzzy image segmentation for urban land-cover classification. Photogrammetric Engineering \& Remote Sensing. 76(2):151-162.

Loveland TR, Reed BC, Brown JF, Ohlen DO, Zhu Z, Yang L, Merchant JW. 2000. Development of a global land cover characteristics database and IGBP DISCover from $1 \mathrm{~km}$ AVHRR data. International Journal of Remote Sensing. 21(6-7):1303-1330.DOI: https://doi.org/10.1080/014311600210191.

Lu D, Mausel P, Brondizio E, Moran E. 2002. Above-ground biomass estimation of successional and mature forests using TM images in the Amazon Basin. In: al. DERe, editor. Advances in spatial data handling. 183-196. : Springer DOI: 10.1007/978-3-642-56094-1_14; p. 183-196.DOI: DOI: 10.1007/978-3-64256094-1_14.

Lu D, Mausel P, Brondizio E, Moran E. 2004. Change detection techniques. International journal of remote sensing. 25(12):2365-2401.DOI: 10.1080/0143116031000139863.

MacLean MG, Congalton RG. 2013. Applicability of Multi-date Land Cover Mapping using Landsat-5 TM Imagery in the Northeastern US. Photogrammetric Engineering \& Remote Sensing. 79(4):359-368.DOI: https://doi.org/10.14358/PERS.79.4.359.

Mahmood R, Pielke RA, Hubbard KG, Niyogi D, Dirmeyer PA, McAlpine C, Carleton AM, Hale R, Gameda S, Beltrán-Przekurat A. 2014. Land cover changes and their biogeophysical effects on climate. International Journal of Climatology. 34(4):929-953.DOI: https://doi.org/10.1002/joc.3736.

Mallinis G, Koutsias N. 2008. Spectral and spatial-based classification for broad-scale land cover mapping based on logistic regression. Sensors. 8(12):8067-8085.DOI: 10.3390/s8128067.

Mallinis G, Koutsias N. 2012. Comparing ten classification methods for burned area mapping in a Mediterranean environment using Landsat TM satellite data. International Journal of Remote Sensing. 33(14):4408-4433.DOI: https://doi.org/10.1080/01431161.2011.648284.

Minh NQ, Hien LP. 2011. Land cover classification using LiDAR intensity data and neural network. Journal of the Korean Society of Surveying, Geodesy, Photogrammetry and Cartography. 29(4):429-438.DOI: 10.7848/ksgpc.2011.29.4.429.

Modica G, Vizzari M, Pollino M, Fichera C, Zoccali P, Di Fazio S. 2012. Spatio-temporal analysis of the urbanrural gradient structure: an application in a Mediterranean mountainous landscape (Serra San Bruno, Italy). Earth Syst Dyn. 3:263-279.DOI: https://doi.org/10.5194/esd-3-263-2012.

$\mathrm{Na}$ X, Zhang S, Li X, Yu H, Liu C. 2010. Improved land cover mapping using random forests combined with landsat thematic mapper imagery and ancillary geographic data. Photogrammetric Engineering \& Remote Sensing. 76(7):833-840.

Nelson GC, Geoghegan J. 2002. Deforestation and land use change: sparse data environments. Agricultural Economics. 27(3):201-216.DOI: https://doi.org/10.1016/S0169-5150(02)00080-4.

Nocita M, Stevens A, van Wesemael B, Aitkenhead M, Bachmann M, Barthès B, Ben Dor E, Brown DJ, Clairotte M, Csorba A et al. 2015. Chapter 4, Soil Spectroscopy: An Alternative to Wet Chemistry for Soil Monitoring. In: Sparks DL, editor. Advances in Agronomy. Academic Press; p. 139-159.DOI: https://doi.org/10.1016/bs.agron.2015.02.002.

Noor NM, Abdullah A, Hashim M. 2011. Classification of Satellite Fused Data for Land Use Mapping in Development Plan. PLANNING MALAYSIA JOURNAL. 9(2).

Pal M. 2006. Support vector machine-based feature selection for land cover classification: a case study with DAIS hyperspectral data. International Journal of Remote Sensing. 27(14):2877-2894.

Palmer MW, McGlinn DJ, Fridley JD. 2008. Artifacts and artifictions in biodiversity research. Folia Geobotanica. 43(3):245-257.

Pandey PC, Anand A, Srivastava PK. 2019. Spatial Distribution of Mangrove Forest species and Biomass Assessment Using Field Inventory and Earth Observation Hyperspectral data. Biodiversity and Conservation. Accepted for publication(Springer).DOI: https://doi.org/10.1007/s10531-019-01698-8.

Pandey PC, Manevski K, Srivastava P, Petropoulos G. 2018. The Use of Hyperspectral Earth observation Data for Land Use/Cover Classification: Present Status, Challenges and Future Outlook. Hyperspectral Remote Sensing of Vegetation, 1st ed; Thenkabail, P, Ed.147-173.

Pandey PC, Rani M, Srivastava PK, Sharma LK, Nathawat MS. 2013. Land degradation severity assessment with sand encroachment in an ecologically fragile arid environment: a geospatial perspective. QScience Connect.43. 
Pandey PC, Sharma LK, Nathawat MS. 2012. Geospatial strategy for sustainable management of municipal solid waste for growing urban environment. Environmental monitoring and assessment. 184(4):24192431.DOI: DOI: 10.1007/s10661-011-2127-2.

Pandey PC, Tate NJ, Balzter H. 2014. Mapping tree species in coastal portugal using statistically segmented principal component analysis and other methods. IEEE Sensors Journal. 14(12):4434-4441.DOI: 10.1109/JSEN.2014.2335612.

Paneque-Gálvez J, Mas J-F, Moré G, Cristóbal J, Orta-Martínez M, Luz AC, Guèze M, Macía MJ, Reyes-García V. 2013. Enhanced land use/cover classification of heterogeneous tropical landscapes using support vector machines and textural homogeneity. International Journal of Applied Earth Observation and Geoinformation. 23:372-383.DOI: https://doi.org/10.1016/j.jag.2012.10.007.

Park J-Y, Shrestha R, Carter W, Tuell G. 2001. Land-cover classification using combined ALSM (LiDAR) and color digital photography ASPRS Conference (St Louis, Missouri, The American Society for Photogrammetry and Remote Sensing) April 2001.

PASCO. 2015. Spaceborne: collecting and analysing geospatial information. Japan; [accessed 201716 November]. http://www.pasco.co.jp/eng/products/worldview-3/.

Petropoulos GP, Arvanitis K, Sigrimis N. 2012. Hyperion hyperspectral imagery analysis combined with machine learning classifiers for land use/cover mapping. Expert systems with Applications. 39(3):38003809.DOI: https://doi.org/10.1016/j.eswa.2011.09.083.

Petropoulos GP, Partsinevelos P, Mitraka Z. 2013. Change detection of surface mining activity and reclamation based on a machine learning approach of multi-temporal Landsat TM imagery. Geocarto International. 28(4):323-342.DOI: https://doi.org/10.1080/10106049.2012.706648.

Piwowar JM. 2011. Principal Earth Observation Satellites \& Sensors. Canada; [accessed 201811 Jan ]. http://uregina.ca/piwowari/Satellites/IRS.html.

Platt RV, Goetz AF. 2004. A comparison of AVIRIS and Landsat for land use classification at the urban fringe. Photogrammetric Engineering \& Remote Sensing. 70(7):813-819.DOI: https://doi.org/10.14358/PERS.70.7.813.

Pohl C, Van Genderen JL. 1998. Review article multisensor image fusion in remote sensing: concepts, methods and applications. International journal of remote sensing. 19(5):823-854.DOI: https://doi.org/10.1080/014311698215748.

Poyatos R, Latron J, Llorens P. 2003. Land use and land cover change after agricultural abandonment: the case of a Mediterranean mountain area (Catalan Pre-Pyrenees). Mountain Research and Development. 23(4):362-368.

Rajadell O, García-Sevilla P, Pla F. 2009. Textural features for hyperspectral pixel classification. Pattern Recognition and Image Analysis.208-216.

Rani M, Kumar P, Pandey PC, Srivastava PK, Chaudhary BS, Tomar V, Mandal VP. 2018. Multi-Temporal NDVI and Surface Temperature Analysis for Urban Heat Island inbuilt surrounding of Sub-humid Region: A Case Study of two Geographical Regions. Remote Sensing Applications: Society and Environment.DOI: https://doi.org/10.1016/j.rsase.2018.03.007.

Rindfuss RR, Walsh SJ, Turner B, Fox J, Mishra V. 2004. Developing a science of land change: challenges and methodological issues. Proceedings of the National Academy of Sciences of the United States of America. 101(39):13976-13981.

Roberts D, Numata I, Holmes K, Batista G, Krug T, Monteiro A, Powell B, Chadwick O. 2002. Large area mapping of land-cover change in Rondônia using multitemporal spectral mixture analysis and decision tree classifiers. Journal of Geophysical Research: Atmospheres. 107(D20):LBA 40-41-LBA 40-18.DOI: 10.1029/2001JD000374.

Rogan J, Miller J, Stow D, Franklin J, Levien L, Fischer C. 2003. Land-cover change monitoring with classification trees using Landsat TM and ancillary data. Photogrammetric Engineering \& Remote Sensing. 69(7):793-804.DOI: https://doi.org/10.14358/PERS.69.7.793.

Saatchi SS, Nelson B, Podest E, Holt J. 2000. Mapping land cover types in the Amazon Basin using 1 km JERS-1 mosaic. International Journal of Remote Sensing. 21(6-7):1201-1234.DOI: https://doi.org/10.1080/014311600210146.

Salehi B, Zhang Y, Zhong M. 2013. A Combined Object-and Pixel-Based Image Analysis Framework for Urban Land Cover Classification of VHR Imagery. Photogrammetric Engineering \& Remote Sensing. 79(11):999-1014.

Serpico SB, Roli F. 1995. Classification of multisensor remote-sensing images by structured neural networks. IEEE Transactions on Geoscience and Remote Sensing. 33(3):562-578. 
Sexton JO, Urban DL, Donohue MJ, Song C. 2013. Long-term land cover dynamics by multi-temporal classification across the Landsat-5 record. Remote Sensing of Environment. 128:246-258.DOI: 10.1016/j.rse.2012.10.010.

Sharma L, Pandey PC, Nathawat M. 2012. Assessment of land consumption rate with urban dynamics change using geospatial techniques. Journal of Land Use Science. 7(2):135-148.DOI: https://doi.org/10.1080/1747423X.2010.537790.

Shen S. 1990. Summary of types of data fusion methods utilized in workshop papers, Multisource Data Integration in Remote Sensing, Proceedings of Workshop.

Simard M, Saatchi SS, De Grandi G. 2000. The use of decision tree and multiscale texture for classification of JERS-1 SAR data over tropical forest. IEEE Transactions on Geoscience and Remote Sensing. 38(5):2310-2321.DOI: 0196-2892(00)08902-6.

Singh KK, Vogler JB, Shoemaker DA, Meentemeyer RK. 2012. LiDAR-Landsat data fusion for large-area assessment of urban land cover: Balancing spatial resolution, data volume and mapping accuracy. ISPRS Journal of Photogrammetry and Remote Sensing. 74:110-121.DOI: 10.1016/j.isprsjprs.2012.09.009.

Singh P, Javed S, Shashtri S, Singh RP, Vishwakarma CA, Mukherjee S. 2017. Influence of changes in watershed landuse pattern on the wetland of Sultanpur National Park, Haryana using remote sensing techniques and hydrochemical analysis. Remote Sensing Applications: Society and Environment. 7:84-92.DOI: https://doi.org/10.1016/j.rsase.2017.07.002.

Singh P, Thakur JK, Kumar S, Singh U. 2011. Assessment of land use/land cover using geospatial techniques in a semi-arid region of Madhya Pradesh, India. Springer and Capital publ, Heidelberg Germany Geos Tech Manag Environ Res.152-163.DOI: DOI 10.1007/978-94-007-1858-6_10,.

Singh S, Tomar V, Pandey P, Rani M, Kumar P. 2018. Geospatial strategy for assessment of urban change dynamics using LISS III-sensor. Bulletin of Environmental and Scientific Research. 3(4):10-17.

Solberg AHS, Taxt T, Jain AK. 1996. A Markov random field model for classification of multisource satellite imagery. IEEE transactions on geoscience and remote sensing. 34(1):100-113.DOI: S 01962892(96)00299-9.

Spies B, Lamb A, Balzter H. 2017. Chapter 5, Multi-Frequency SAR Applications for Land Cover Classification Within Copernicus Downstream Services. Earth observation for land and emergency monitoring. John Wiley \& Sons; p. 77.

Srivastava PK, Han D, Rico-Ramirez MA, Bray M, Islam T. 2012. Selection of classification techniques for land use/land cover change investigation. Advances in Space Research. 50(9):1250-1265.DOI: https://doi.org/10.1016/j.asr.2012.06.032.

St-Louis V, Pidgeon AM, Clayton MK, Locke BA, Bash D, Radeloff VC. 2009. Satellite image texture and a vegetation index predict avian biodiversity in the Chihuahuan Desert of New Mexico. Ecography. 32(3):468-480.

Stamou Z, Xystrakis F, Koutsias N. 2016. The role of fire as a long-term landscape modifier: Evidence from longterm fire observations (1922-2000) in Greece. Applied Geography. 74:47-55.DOI: http://dx.doi.org/10.1016/j.apgeog.2016.07.005.

Stefanov WL, Ramsey MS, Christensen PR. 2001. Monitoring urban land cover change: An expert system approach to land cover classification of semiarid to arid urban centers. Remote sensing of Environment. 77(2):173-185.DOI: https://doi.org/10.1016/S0034-4257(01)00204-8.

Stevens A, van Wesemael B, Bartholomeus H, Rosillon D, Tychon B, Ben-Dor E. 2008. Laboratory, field and airborne spectroscopy for monitoring organic carbon content in agricultural soils. Geoderma. 144(12):395-404.DOI: https://doi.org/10.1016/j.geoderma.2007.12.009.

Tan KC, San Lim H, MatJafri MZ, Abdullah K. 2010. Landsat data to evaluate urban expansion and determine land use/land cover changes in Penang Island, Malaysia. Environmental Earth Sciences. 60(7):15091521.DOI: 10.1007/s12665-009-0286-z.

Tan Q, Wang J. 2007. Hyperspectral Versus Multispectral Satellite Data For Urban Land Cover And Land Use Mapping-Beijing, An Evolving City. ASPRS 2007 Annual Conference; 2007; Tampa, Florida ,May 7 11, 2007.

Tarabalka Y, Chanussot J, Benediktsson JA. 2010. Segmentation and classification of hyperspectral images using minimum spanning forest grown from automatically selected markers. IEEE Transactions on Systems, Man, and Cybernetics, Part B (Cybernetics). 40(5):1267-1279.DOI: 10.1109/TSMCB.2009.2037132. 
1161

1162

1163

1164

1165

1166

1167

1168

1169

1170

1171

1172

1173

1174

1175

1176

1177

1178

1179

1180

1181

1182

1183

1184

1185

1186

1187

1188

1189

1190

1191

1192

1193

1194

1195

1196

1197

1198

1199

1200

1201

1202

1203

1204

1205

1206

1207

1208

1209

1210

1211

1212

1213

1214

Tegene B. 2002. Land-cover/land-use changes in the derekolli catchment of the South Welo Zone of Amhara Region, Ethiopia. Eastern Africa Social Science Research Review. 18(1):1-20.DOI: https://doi.org/10.1353/eas.2002.0005.

Thenkabail PS, Enclona EA, Ashton MS, Legg C, De Dieu MJ. 2004. Hyperion, IKONOS, ALI, and ETM+ sensors in the study of African rainforests. Remote Sensing of Environment. 90(1):23-43.DOI: https://doi.org/10.1016/j.rse.2003.11.018.

Thenkabail PS, Lyon JG. 2016. Hyperspectral remote sensing of vegetation. CRC press.

Thenkabail PS, Schull M, Turral H. 2005. Ganges and Indus river basin land use/land cover (LULC) and irrigated area mapping using continuous streams of MODIS data. Remote Sensing of Environment. 95(3):317341.DOI: 10.1016/j.rse.2004.12.018.

Theobald DM, Crooks KR, Norman JB. 2011. Assessing effects of land use on landscape connectivity: loss and fragmentation of western US forests. Ecological Applications. 21(7):2445-2458.DOI: https://doi.org/10.1890/10-1701.1.

Trisurat Y, Alkemade R, Verburg PH. 2010. Projecting land-use change and its consequences for biodiversity in Northern Thailand. Environmental Management. 45(3):626-639.DOI: https://doi.org/10.1007/s00267010-9438-x.

Tu J. 2011. Spatially varying relationships between land use and water quality across an urbanization gradient explored by geographically weighted regression. Applied Geography. 31(1):376-392.DOI: https://doi.org/10.1016/j.apgeog.2010.08.001.

Tucker CJ, Grant DM, Dykstra JD. 2004. NASA's global orthorectified Landsat data set. Photogrammetric Engineering \& Remote Sensing. 70(3):313-322.DOI: https://doi.org/10.14358/PERS.70.3.313.

Uriarte M, Yackulic CB, Lim Y, Arce-Nazario JA. 2011. Influence of land use on water quality in a tropical landscape: a multi-scale analysis. Landscape ecology. 26(8):1151.DOI: https://doi.org/10.1007/s10980-011-9642-y.

Vargo J, Habeeb D, Stone B. 2013. The importance of land cover change across urban-rural typologies for climate modeling. Journal of environmental management. 114:243-252.DOI: https://doi.org/10.1016/j.jenvman.2012.10.007.

Vijayan D, Shankar GR, Shankar TR. 2014. Hyperspectral Data for Land use/Land cover classification. The International Archives of Photogrammetry, Remote Sensing and Spatial Information Sciences. 40(8):991.DOI: 10.5194/isprsarchives-XL-8-991-2014.

Weng Q. 2002. Land use change analysis in the Zhujiang Delta of China using satellite remote sensing, GIS and stochastic modelling. Journal of Environmental Management. 64(3):273-284.DOI: http://dx.doi.org/10.1006/jema.2001.0509.

Werner A, Storie CD, Storie J. 2014. Evaluating SAR-optical image fusions for urban LULC classification in Vancouver Canada. Canadian Journal of Remote Sensing. 40(4):278-290.DOI: 10.1080/07038992.2014.976700.

White JC, Gómez C, Wulder MA, Coops NC. 2010. Characterizing temperate forest structural and spectral diversity with Hyperion EO-1 data. Remote Sensing of Environment. 114(7):1576-1589.

Whyte A, Ferentinos KP, Petropoulos GP. 2018. A new synergistic approach for monitoring wetlands using Sentinels- 1 and 2 data with object-based machine learning algorithms. Environmental Modelling \& Software. 104:40-54.DOI: https://doi.org/10.1016/j.envsoft.2018.01.023.

Wu C, Du B, Cui X, Zhang L. 2017. A post-classification change detection method based on iterative slow feature analysis and Bayesian soft fusion. Remote Sensing of Environment. 199:241-255.DOI: https://doi.org/10.1016/j.rse.2017.07.009.

Xystrakis F, Psarras T, Koutsias N. 2017. A process-based land use/land cover change assessment on a mountainous area of Greece during 1945-2009: Signs of socio-economic drivers. Science of The Total Environment. 587-588:360-370.DOI: https://doi.org/10.1016/j.scitotenv.2017.02.161.

Yan WY, Shaker A, El-Ashmawy N. 2015. Urban land cover classification using airborne LiDAR data: A review. Remote Sensing of Environment. 158:295-310.DOI: https://doi.org/10.1016/j.rse.2014.11.001.

Zaidi SM, Akbari A, Abu Samah A, Kong NS, Gisen A, Isabella J. 2017. Landsat-5 Time Series Analysis for Land Use/Land Cover Change Detection Using NDVI and Semi-Supervised Classification Techniques. Polish Journal of Environmental Studies. 26(6).DOI: 10.15244/pjoes/68878.

Zhang B, Zhang Q, Feng C, Feng Q, Zhang S. 2017. Understanding Land Use and Land Cover Dynamics from 1976 to 2014 in Yellow River Delta. Land. 6(1):20.DOI: https://doi.org/10.3390/land6010020. 
Zhu Z. 2017. Change detection using landsat time series: A review of frequencies, preprocessing, algorithms, and applications. ISPRS Journal of Photogrammetry and Remote Sensing. 130:370-384.DOI: https://doi.org/10.1016/j.isprsjprs.2017.06.013.

Zhu Z, Woodcock CE, Rogan J, Kellndorfer J. 2012. Assessment of spectral, polarimetric, temporal, and spatial dimensions for urban and peri-urban land cover classification using Landsat and SAR data. Remote Sensing of Environment. 117:72-82.DOI: https://doi.org/10.1016/j.rse.2011.07.020.

Zucca C, Canu A, Previtali F. 2010. Soil degradation by land use change in an agropastoral area in Sardinia (Italy). Catena. 83(1):46-54.DOI: https://doi.org/10.1016/j.catena.2010.07.003. 